
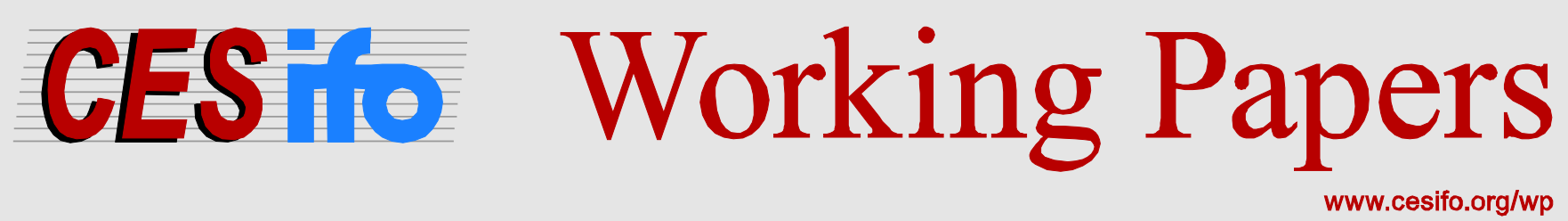

\title{
Regional Implications of Financial Market Development: Credit Rationing, Trade, and Location
}

\author{
Maximilian von Ehrlich \\ Tobias Seidel
}

CESIFO WORKING PAPER NO. 4063

Category 8: Trade Policy

JANUARY 2013

An electronic version of the paper may be downloaded

- from the SSRN website:

- from the RePEc website:

- from the CESifo website:

wWw.SSRN.com

www.RePEc.org

www.CESifo-group.org/wp

\section{CESifo}




\title{
Regional Implications of Financial Market Development: Credit Rationing, Trade, and Location
}

\begin{abstract}
We develop a heterogeneous-firms model with trade in goods, labor mobility and credit constraints due to moral hazard. Mitigating financial frictions reduces the incentive of highskilled workers to migrate to one region such that an unequal distribution of industrial activity becomes less likely. Hence, financial market development has opposite regional implications as trade liberalization. While the former leads to more dispersion of economic activity across space, the latter tends to drive clustering. We provide empirical evidence for this hypothesis by combining industry-region variation in the spatial concentration of economic activity with information on the access to credit and the dependence on external finance. Our estimates for 20 European countries and eleven industries confirm that financial market development mitigates the clustering of economic activity.
\end{abstract}

JEL-Code: F120, F360, R110.

Keywords: financial market development, credit constraints, moral hazard, location, migration, heterogeneous firms, trade, labor mobility.

Maximilian von Ehrlich ETH Zurich

Department of Management, Technology and Economics, WEH F9

Weinbergstrasse 35

Switzerland - 8092 Zurich

vonehrlich@kof.ethz.ch
Tobias Seidel

University of Duisburg-Essen

Department of Economics

Mercator School of Management

Lotharstraße 65

Germany - 47057 Duisburg

tobias.seidel@uni-due.de 


\section{Introduction}

There has been a long and still unsettled debate whether the integration of markets leads to a more or less equal distribution of economic activity and thus wealth across regions. While the conventional view suggests that market integration should lead to convergence and thus more equal living conditions, there is also a prominent opposition claiming that globalization increases inequality (Myrdal, 1957, Lewis, 1977). There is surprisingly little work that links the role of financial markets to this debate. It is surprising because the importance of the financial sector for the real economy is widely acknowledged and we have seen a very pronounced development of financial markets in recent decades.

One attempt to reconcile these two views in the context of financial markets is Matsuyama (2004). He develops an overlapping-generations model with credit market imperfection and investment. He shows that financial markets may cause inequality as symmetric equilibria become unstable and regions separate into rich and poor. We build a different model where integrated product and labor markets play a key role and find the opposite result: Financial market development leads to a more equal distribution of industrial production and hence, real income. Intuitively, improving access to external finance renders exporting more profitable which, in turn, makes it less important to be located in the larger market. This result has important implications for public policies. Politicians are often concerned about regional policy to ensure "equal" living conditions across jurisdictions. According to our findings financial market development can complement policies aiming at regional cohesion because improvements in the access to external finance mitigate the incentives for economic activity to cluster in one region.

Our model features trade in goods, labor migration, credit constraints, endogenous entry and exit of heterogeneous firms, and occupational choice (for the latter see Egger and Kreickemeier, 2008, 2012). The financial friction stems from a moral-hazard problem in the tradition of Holmstrom and Tirole (1997). While entrepreneurs can choose their effort level to maximize their payoff, lenders cannot directly observe the managers' behavior. Hence, asymmetric information introduces credit constraints as lenders demand a higher return from a given investment to ensure a higher payoff for entrepreneurs and thus diligent behavior. This leads to credit rationing as less-productive firms cannot convince lenders not to shirk. To obtain these selection effects, we need to introduce some kind of firm heterogeneity. We deviate from Holmstrom and Tirole (1997) in ignoring different 
endowments of firm assets, but rather follow Melitz (2003) in introducing different levels of productivity (see also Pflüger and Südekum, 2013). This helps us capturing the stylized fact that some firms are more credit constrained than others with some even being excluded from the credit market.

The building blocks of our model are strongly supported by empirical evidence. There is a growing literature in international economics that has identified financial market development as an important determinant of trade flows and foreign direct investment (FDI). Lower credit constraints generate a comparative advantage (Egger and Keuschnigg, 2010a and 2010b) and lead to more exports both in terms of volume and destinations (Beck 2002 and 2003, Manova, 2008 and 2012, Muûls, 2008). ${ }^{1}$ Further, several influential empirical papers have identified economic determinants for the location of industry. For example, Davis and Weinstein (2002) show that locational fundamentals are crucial for the pattern of economic activity across space, but increasing returns to scale determine the intensity of concentration. Ellison, Glaeser and Kerr (2010) disentangle the three Marshallian explanations for agglomeration: (i) technology spillovers, (ii) labor market pooling, and (iii) proximity to input suppliers (vertical linkages) to save transport costs. They find that the latter features most prominently in the data. Even though input-output linkages are not present in our model, it can be shown that the resulting location pattern results from the same forces as in Krugman (1991) on which we build. Moreover, Davis and Weinstein (2003), Hanson and Xiang (2004) and Redding and Sturm (2008) provide convincing evidence for the home-market effect which is at the center of the location mechanism in our model.

The role of market integration for inequality has been addressed in a number of literatures. In finance, for example, Acemoglu and Zillibotti (1997) as well as Martin and Rey (2004) argue that rich countries have more developed financial markets providing better diversification and thus higher investment levels. This mechanism contributes to a widening gap between rich and poor countries. An early example from the growth literature is Krugman (1981) pointing out that a difference in capital-labor ratios magnifies due to capital accumulation over time. This process contributes to more inequality between

\footnotetext{
${ }^{1}$ Chor, Foley, and Manova (2008) show that development of financial markets in the host country reduces horizontal FDI due to more entry and thus competition of local firms, but stimulates affiliate sales to third countries. For example, Antràs and Caballero (2009) show that trade and capital flows may be complements in classical trade theory under financial frictions. Antràs, Desai, and Foley (2009) examine how weak investor protection and financial frictions affect the prevalence of multinational firms and the international financing of investment.
} 
regions. There is also a large literature on trade and labor that studies the role of trade liberalization for wage inequality between workers with different skills and even within groups having the same skills (Felbermayr, Prat and Schmerer, 2011, Egger and Kreickemeier, 2008, 2012, Helpman and Itskhoki, 2010, and Helpman, Itskhoki, and Redding, 2010). Finally, it is by now well-understood how trade liberalization affects the migration decision of production factors in the context of international goods trade (Krugman, 1991, and Krugman and Venables, 1995). Except for the finance literature, none of these papers focuses on the role of financial frictions which is at the heart of our paper. ${ }^{2}$

A further contribution of our paper is that we provide reduced-form evidence for the hypothesis derived in the theoretical model. While the role of financial markets has been studied for various outcomes such as economic growth, R\&D intensity, or FDI (see e.g. Carlin and Mayer, 2003; Alfaro, Chanda, Kalemli-Ozcan, and Sayek, 2004; Maskus, Neumann, and Seidel, 2012) there is no empirical study that relates to our theoretical finding of symmetric financial rigidities fostering the concentration of economic activity across regional entities. ${ }^{3}$ Accordingly, in the second part of this paper we provide empirical evidence for financial market development on the country level to reduce the concentration of economic activity within countries. We follow the econometric approach of Rajan and Zingales (1998) in interacting an industry measure of external financial dependence with a country variable of financial market development. Linking this term to alternative measures of spatial concentration of economic activity across countries and industries, we find robust evidence for financial market development to reduce the degree of spatial concentration. Our estimates suggest that the difference in the degree of agglomeration between two industries with different degrees of external financial dependence diminishes significantly once the general access to credit is facilitated.

The paper is organized as follows. In the next section, we introduce a model of trade, labor mobility, and credit constraints. In Section 3, we derive equilibrium conditions and solve the model in section 4. The empirical analysis is laid out in section 5. Section 6

\footnotetext{
${ }^{2} \mathrm{~A}$ recent example of moral hazard and factor mobility, but without credit rationing, is Hakenes and Kranich (2010). Credit constraints affect the pattern of agglomeration simply through a cost effect while our model features complex selection effects altering average industry productivity, the number of firms as well as the share of exporters. This turns out essential for the equilibrium distribution of economic activity. Finally, our model entails a richer set of economic motives that drive the location decision of workers.

${ }^{3}$ Note that our theoretical model implies that a symmetric increase in the supply of credit across two regional entities yields a more dispersed distribution of economic activity. This differs crucially from an evaluation of region-specific financial market development which may stimulate economic activity in that region and raise inequality compared to regions that did not experience such development.
} 
concludes with a summary of the main findings and implications for regional policy.

\section{The model}

Consider two regions $i$ and $j$ that are endowed with immobile low-skilled $(L)$ and mobile high-skilled workers $(H)$. Both regions are identical ex ante, but may differ ex post due to migration of high-skilled workers. This gives rise to an endogenous allocation of industries across space (see Krugman, 1991). Unless otherwise stated, we report expressions for region $i$ stressing that similar equations exist for region $j$.

\subsection{Preferences and demand}

Individuals derive utility from consuming two goods, a homogeneous good $Y$ and a differentiated commodity $Q$, where the level of utility is determined by

$$
U_{i}=Q_{i}^{\alpha} Y_{i}^{1-\alpha}
$$

The differentiated good is composed of a mass $V$ of varieties $v$ that are aggregated according to $Q_{i}=\left(\int_{v \in V} q_{i}(v)^{\frac{\sigma-1}{\sigma}} d v\right)^{\frac{\sigma}{\sigma-1}}$. Note that $V$ is determined endogenously in general equilibrium and $\sigma$ represents the constant elasticity of substitution between any two varieties. Further, $q_{i}(v)$ describes the consumption level of variety $v$ in region $i$ - which may be a local or a foreign type.

Maximizing (1) subject to the budget constraint delivers total demand for a variant of the differentiated commodity

$$
q_{i}(v)=\frac{p_{i}(v)^{-\sigma}}{P_{i}^{1-\sigma}} \alpha E_{i}
$$

where $P_{i}=\left[\int_{v \in V} p_{i}(v)^{1-\sigma} d v\right]^{1 /(1-\sigma)}$ denotes the price index, $p_{i}(v)$ represents the consumer price for variety $v$ in country $i$ and $E_{i}$ is individual expenditure for consumption (which is equal to income). With Cobb-Douglas preferences, each individual spends a constant income share on each good such that $Q_{i}=\alpha E_{i} / P_{i}$ and $Y_{i}=(1-\alpha) E_{i} / P_{Y i}$. 
Plugging these demand functions into (1) yields indirect utility

$$
W_{i}=\frac{\alpha^{\alpha}(1-\alpha)^{1-\alpha} E_{i}}{P_{i}^{\alpha} P_{Y i}^{1-\alpha}} .
$$

\subsection{Technology and organizational choice}

The homogeneous good is sold in a perfectly competitive market and requires low-skilled labor as the only input. We assume that one unit of low-skilled labor is required to produce one unit of output. Choosing $Y$ as the numéraire and imposing zero trade costs across borders implies that the price for $Y$ is equal to unity in both regions and so are wages of low-skilled workers.

The manufacturing sector is characterized by monopolistic competition using highskilled workers as the only factor of production. Fixed production costs generate increasing returns to scale such that each company exclusively manufactures one commodity for the market. High-skilled workers have the choice between founding a firm (and becoming an entrepreneur) and working as an employee. However, the productivity level of the firm, $\varphi$, is not known ex ante so that in equilibrium workers are indifferent between earning the expected payoff from becoming an entrepreneur and the observed wage rate. As long as the expected payoff is greater than the observed wage rate there will be a high-skilled worker who finds it profitable to participate in the lottery and to become with a certain probability an active entrepreneur. A high value of $\varphi$ implies a low number of workers $h_{i}$ to produce one unit of output, $q_{i}(\varphi)=\varphi h_{i}$. Further, high-productive firms earn strictly higher profits than low-productive firms (which we show formally below). We follow the literature on heterogeneous firms by assuming that $\varphi$ follows a commonly-known distribution function of the Pareto type, that is $G(\varphi)=1-\varphi^{-k}$, where $k$ captures the shape parameter. We have further normalized the scale parameter to one to simplify notation.

High-skilled workers have an incentive to participate in the productivity lottery as long as expected firm profits exceed their opportunity costs, that is the wage rate $w_{i}$ they could earn as an employee in the manufacturing industry. ${ }^{4}$ This builds on the assumption that entrepreneurs cannot seek employment in one of the manufacturing firms once they have decided to establish a firm. ${ }^{5}$ If their obtained productivity level implies profits, they start

\footnotetext{
${ }^{4}$ We derive this condition formally below.

${ }^{5}$ Egger and Kreickemeier (2012) make a similar assumption.
} 
producing. If $\varphi$ is too low, they exit again and end up without income.

Those entrepreneurs with sufficiently high productivity choose between two organizational modes. They can either solely serve domestic consumers or decide to produce for the export market in addition. We refer to the former type as domestic firms (superscript $d$ ) and to the latter firm type as exporting firms (superscript $x$ ). Both organizational forms imply different levels of fixed costs. To serve consumers domestically, companies need to incur $f^{d}$ units of high-skilled labor while exporting requires an additional fixed investment of the same factor so that $f^{x}>f^{d}$. Shipping goods to the other region is subject to iceberg transport costs implying that $\tau>1$ units of the final good have to be sent for one unit to arrive at the final destination abroad. The choice between domestic sales only and additional exporting is governed by profits of each of these activities which we derive in subsection 2.4 below.

\subsection{Credit market}

Firms crucially rely on external finance to start their operations. In particular, we assume that companies need to secure external finance for fixed costs while variable costs can be covered by means of cash flow from sales. Credit is provided by a perfectly-competitive banking sector. If a high-skilled worker has chosen to become an entrepreneur and to found a domestic firm, she needs $f^{d} w_{i}$ of external finance. If she chooses an exporting type, she requires $f^{x} w_{i}$. Writing a financial contract on these fixed investments implies asymmetric information between the lender and the borrower. In particular, we assume that banks cannot observe the chosen effort level of the entrepreneur. Following Holmstrom and Tirole (1997), the entrepreneur can choose to behave diligently implying a probability of making profits of $\psi_{b}<1$. Alternatively, she can opt for shirking which reduces the probability of making profits to $0<\psi_{s}<\psi_{b}$, but promises private benefits $B w_{i}$ that we express in terms of high-skilled wages. ${ }^{6}$ As the lender can neither observe the chosen effort level nor proof ex post whether the manager has shirked, financial contracts are subject to a moral-hazard problem. The entrepreneurs who do not succeed in making profits are hit by a stochastic shock which forces them to exit before entering production. While the probability of being hit by the bad shock can be reduced from $1-\psi_{s}$ to $1-\psi_{b}$ by diligent behavior, it is equally distributed across productivities. In contrast to Holmstrom and Tirole (1997), firms differ

\footnotetext{
${ }^{6}$ Alternatively, we could denote private benefits in terms of the numéraire which would not affect results qualitatively. However, this specification yields less complex expressions enhancing readability.
} 
in their productivity which determines their access to external funding. We thus do not need to impose asymmetric endowments of assets across entrepreneurs and normalize their value to zero.

Provided the borrower works with high effort, the lender is only willing to grant the loan if the expected payoff from doing so covers the principal. Denoting by $R_{i}^{\ell}$ the return to the bank for a loan to a domestic firm $(\ell=d)$ and an exporting firm $(\ell=x)$, respectively, we can express the zero-profit condition for the lenders as

$$
\psi_{b} R_{i}^{\ell}=f^{\ell} w_{i}
$$

The rate of return $\rho$ of such an investment is given by $R_{i}^{\ell}=(1+\rho) f^{\ell} w_{i}$. Combining both equations delivers $1+\rho=1 / \psi_{b}$. As $\psi_{b}<1, \rho$ is strictly positive reflecting a risk premium that compensates for credit default of unsuccessful firms.

To avoid losses from lending, the bank has to make sure that the expected income of the entrepreneur is sufficiently high so that she can repay the principal plus the risk premium. We assume that the marginal firm only has a positive net present value if the entrepreneur behaves. Hence, the bank has to rule out shirking by allowing a sufficiently high income to the entrepreneur. We refer to this condition as the incentive compatibility constraint (IC). For domestic firms, this is given by

$$
\psi_{b}\left[\frac{r_{i}^{\ell}\left(\varphi_{i}\right)}{\sigma}-R_{i}^{\ell}\right] \geq \psi_{s}\left[\frac{r_{i}^{\ell}\left(\varphi_{i}\right)}{\sigma}-R_{i}^{\ell}\right]+B w_{i}
$$

The term in brackets denotes the income of the entrepreneur, that is the difference between operating profits $r_{i}^{\ell}(\varphi) / \sigma$ and the repayment to the bank $R_{i}^{l}$ where operating profits are strictly increasing in productivity. Hence, the entrepreneur can pledge only a fraction of her income to the lenders without violating the incentive compatibility constraint, namely $r_{i}^{\ell}(\varphi) / \sigma-B w_{i} / \Delta \psi$, where we have defined $\Delta \psi \equiv \psi_{b}-\psi_{s}$. Firms with a higher productivity than the marginal firm may earn expected profits that suffice to repay the principal even under shirking. As diligent behavior implies strictly higher expected profits, though, shirking is never an appealing option for these entrepreneurs. ${ }^{7}$

To ensure zero profits of banks, the expected pledgeable income must not fall short of

\footnotetext{
${ }^{7}$ Since the marginal firm that meets $(I C)$ cannot repay the principal plus risk premium under shirking, firms that are capable of doing so must have greater operating profits than the marginal firm. This in turn implies a higher pledgeable income without violating $(I C)$.
} 
the principal. We refer to this condition as the participation constraint (PC) which can be expressed as

$$
\psi_{b}\left[\frac{r_{i}^{\ell}(\varphi)}{\sigma}-\frac{B w_{i}}{\Delta \psi}\right] \geq f^{\ell} w_{i}
$$

We observe from $(P C)$ that banks are only willing to allow a credit if the entrepreneur generates operating profits that cover at least $B w_{i} / \Delta \psi+f^{\ell} w_{i} / \psi_{b}$. As operating profits increase in productivity (which we show in the following subsection), only more productive companies receive external finance. In contrast to a world without moral hazard, some entrepreneurs are unable to secure external funding to pay for fixed costs because they cannot commit to behave diligently. Even if they offered a higher risk premium to the lender, the bank would not grant the loan as the remaining income of the entrepreneur would be too low to meet the incentive compatibility constraint. Hence, entrepreneurs that do not meet $(P C)$ due to a too low productivity level cannot start producing and thus end up with no income. As entrepreneurs are able to raise funds from a perfectly competitive banking sector, those that satisfy $(P C)$ offer the lowest possible claim to the lender that meets $(I C)$, that is $R_{i}^{\ell}=f^{\ell} w_{i}(1+\rho){ }^{8}$ This result shows that the entrepreneur receives the entire surplus if the project is funded.

The model features two determinants of credit constraints: Firm productivity and agency costs. First, firms are more likely to receive outside finance if they are more productive and thus larger. As profits strictly increase in $\varphi$, more productive firms leave the entrepreneur with a higher income inducing her to behave. Second, agency costs determine the entrepreneurs' ability to borrow. These costs are determined by a combination of private benefits and the success probabilities under diligence and shirking and can be measured by $c w_{i}$, where we introduce the agency cost parameter $c \equiv \psi_{b} B / \Delta \psi$ on which we rely repeatedly in the subsequent analysis. We observe from $(P C)$ that this term captures the non-pledgeability of income. The higher the value, the more difficult it is to secure external finance for a given level of expected operating profits. With respect to the first component of agency costs, a higher level of private benefits $B w_{i}$ requires a higher income of the entrepreneur to make diligent behavior more attractive than shirking. The second part of agency costs comprises the inverse of the likelihood ratio $\Delta \psi / \psi_{b}$. According to Tirole (2006), the likelihood ratio measures the reduction in the probability of success if the entrepreneur decides to shirk which can also be interpreted as the marginal productivity

\footnotetext{
${ }^{8}$ Her income is then given by $r_{i}^{\ell}(\varphi) / \sigma-f^{\ell} w_{i}(1+\rho) \geq B w_{i} / \Delta \psi$ which is a reformulation of $(I C)$.
} 
of behaving diligently. As lenders can infer better the behavior of borrowers at a high likelihood ratio, it is easier for entrepreneurs to get access to external finance in this case. This definition of agency costs is our key measure of the severeness of credit constraints to which we refer repeatedly in the following analysis.

\subsection{Profits}

We have claimed so far that profits increase with productivity $\varphi$. In this subsection, we derive profits of both domestic firms $(\ell=d)$ and exporting firms $(\ell=x)$ that govern the entrepreneurs' choice of firm types. As firms face a constant price elasticity of demand, profit-maximizing prices are chosen as constant mark-ups over variable costs. For domestic sales and exports, we respectively have

$$
p_{i i}(\varphi)=\frac{\sigma w_{i}}{(\sigma-1) \varphi} \quad p_{i j}(\varphi)=\frac{\sigma \tau w_{i}}{(\sigma-1) \varphi}
$$

where the first subscript always refers to the place of production and the second subscript to the place of sale. Revenues and profits for each market are given by

$$
\begin{array}{ll}
r_{i i}(\varphi)=\frac{p_{i i}(\varphi)^{1-\sigma}}{P_{i}} \alpha E_{i} & r_{i j}(\varphi)=\frac{p_{i j}(\varphi)^{1-\sigma}}{P_{j}} \alpha E_{j} \\
\pi_{i i}(\varphi)=r_{i i}(\varphi) / \sigma-f^{d} w_{i}(1+\rho) & \pi_{i j}(\varphi)=r_{i j}(\varphi) / \sigma-\left(f^{x}-f^{d}\right) w_{i}(1+\rho),
\end{array}
$$

where we have accounted for the risk premium firms need to pay on their fixed costs. Since each firm type has to earn at least $B w_{i} / \Delta \psi$ plus the respective fixed costs $f^{\ell} w_{i}(1+\rho)$, the decision to become an exporter is affected by the moral-hazard problem only to the extent that the additional fixed costs $\left(f^{x}-f^{d}\right) w_{i}(1+\rho)$ have to be financed via bank loans (including the risk premium). As long as operating profits from exporting do not fall short of the extra credit costs, it pays for an entrepreneur to export. We derive the export productivity cutoff $\varphi_{i j}^{*}$ by using the condition $\pi_{i}^{x}\left(\varphi_{i j}^{*}\right)=\pi_{i}^{d}\left(\varphi_{i j}^{*}\right)$ which is equivalent to

$$
\frac{r_{i j}\left(\varphi_{i j}^{*}\right)}{\sigma}=\left(f^{x}-f^{d}\right) w_{i}(1+\rho) .
$$

Hence, an entrepreneur with productivity draw $\varphi_{i j}^{*}$ is indifferent between paying the higher fixed costs $f^{x}$ to become an exporter and paying the lower fixed costs $f^{d}$ to serve only 
the domestic market. Every entrepreneur with productivity draw beyond $\varphi_{i j}^{*}$ decides to set up an exporting firm. Note that the participation constraint (PC) is always met for an entrepreneur who drew a productivity $\varphi>\varphi_{i j}^{*}$ and accordingly decides to establish an exporting firm. ${ }^{9}$

\section{Equilibrium}

To determine equilibria, we proceed as follows. We first assume that both regions are able to trade both goods while high-skilled workers are immobile. We refer to this case as the short run. In a second step, we derive the long-run equilibrium where high-skilled workers choose their region of residence and employment based on real wages. We discuss both cases sequentially in the following two subsections.

\subsection{Immobile workers}

To describe the equilibrium, we need to derive the productivity cutoff $\varphi_{i i}^{*}$, that is the productivity level of the least efficient (marginal) producer, as well as equilibrium wages and the number of firms.

Domestic productivity cutoff. To obtain $\varphi_{i i}^{*}$, we combine the free-entry condition $(F E)$ with the marginal-credit-access condition $(M C A)$. In contrast to Melitz (2003), $M C A$ substitutes for the zero-cutoff profit condition because the marginal firm in our model is determined by getting access to external finance rather than by zero profits. Here, the marginal firm earns strictly positive profits in the presence of moral hazard.

High-skilled workers enter the industry as entrepreneurs until expected profits equal entry costs, that is their opportunity cost from working as an employee in the $Q$-sector, $w_{i}$. Formally, this condition reads

$$
\psi_{b}\left(\varphi_{i i}^{*}\right)^{-k} \bar{\pi}_{i}=w_{i}
$$

The left-hand side describes average profits from domestic sales and exporting condi-

\footnotetext{
${ }^{9}$ Under exporting, operating profits are $r_{i}^{x}(\varphi) / \sigma=r_{i}^{d}(\varphi) / \sigma+r_{i j}(\varphi) / \sigma$ while fixed costs become $w_{i}(1+$ $\rho)\left[f^{d}+\left(f^{x}-f^{d}\right)\right]$ such that the participation constraint reads $\psi_{b}\left[r_{i}^{d}(\varphi) / \sigma+r_{i j}(\varphi) / \sigma-B w_{i} / \Delta \psi\right] \geq w_{i} f^{x}$. Accordingly, if (PC) is fulfilled for the domestic firm type it must be fulfilled for the exporting firm type as well because $\varphi>\varphi_{i j}^{*}$ from (5).
} 
tional on surviving in competition, $1-G\left(\varphi_{i i}^{*}\right)=\left(\varphi_{i i}^{*}\right)^{-k}$, and not being hit by the exogenous shock of failure $\psi_{b}$. Surviving firms can expect to earn $\pi_{i i}\left(\tilde{\varphi}_{i i}\right)$ domestically and $\left(\varphi_{i i}^{*} / \varphi_{i j}^{*}\right)^{k} \pi_{i j}\left(\tilde{\varphi}_{i j}\right)$ from exports where $\left(\varphi_{i i}^{*} / \varphi_{i j}^{*}\right)^{k}$ reflects the probability of becoming an exporter conditional on being active in the domestic market. Further, $\tilde{\varphi}_{i i}$ and $\tilde{\varphi}_{i j}$ represent average productivity levels of all operating firms and those that export, respectively. Due to the Pareto distribution, $\tilde{\varphi}_{i i} / \varphi_{i i}^{*}=\tilde{\varphi}_{i j} / \varphi_{i j}^{*}=[k /(k-\sigma+1)]^{1 /(\sigma-1)}$ holds as a constant relationship between average and cutoff productivities. ${ }^{10}$

It is convenient to express the probability of exporting in terms of domestic productivity cutoffs only. To do this, we derive operating profits of the marginal firm that secures external finance. From the participation constraint $(P C)$ we get

$$
\frac{r_{i i}\left(\varphi_{i i}^{*}\right)}{\sigma}=f^{d} w_{i}(1+\rho)+B w_{i} / \Delta \psi .
$$

Entrepreneurs with a productivity draw below $\varphi_{i i}^{*}$ will not obtain credit and accordingly do not succeed in setting up their firm. Using (6) jointly with (5) and $r_{j i}\left(\varphi_{j i}^{*}\right)=$ $r_{i i}\left[\left(\varphi_{j i}^{*} w_{i}\right) /\left(\tau w_{j}\right)\right]$, we can establish the following link between the export cutoff in $j$ and the domestic cutoff in $i$ :

$$
\varphi_{j i}^{*}=\tau\left(\frac{f^{x}-f^{d}}{f^{d}+c}\right)^{\frac{1}{\sigma-1}}\left(\frac{w_{j}}{w_{i}}\right)^{\frac{\sigma}{\sigma-1}} \varphi_{i i}^{*} .
$$

Recall that the agency cost parameter $c$ measures the severeness of the credit constraint. It is immediate that an increase in foreign wages lowers the export cutoff ceteris paribus. Domestic firms become relatively more competitive and more firms export. To ensure that exporting firms also serve local consumers, we restrict the parameter space to $\left(f^{x}-\right.$ $\left.f^{d}\right) /\left(f^{d}+c\right)>1 .^{11}$ It is thus evident that the conditional export probability is limited to range between zero and unity. Taking region $i$ 's export cutoff based on (7), we can

\footnotetext{
${ }^{10}$ For deriving the average productivity we assume $k>\sigma-1$. Technically, this is to ensure that the integral over the productivities converges and represent a standard assumption in the literature on trade and heterogeneous firms.

${ }^{11}$ Note that for symmetric regions $w_{i}=w_{j}$ and $\varphi_{i i}^{*}=\varphi_{j j}^{*}$ such that $\varphi_{j i}^{*}>\varphi_{i i}^{*}$ implies $\varphi_{j i}^{*}>\varphi_{j j}^{*}$ and $\varphi_{i j}^{*}>\varphi_{j j}^{*}$ implies $\varphi_{i j}^{*}>\varphi_{i i}^{*}$. For the general case with asymmetric regions, requiring that firms also serve the domestic market when exporting - i.e. $\varphi_{j i}^{*}>\varphi_{i i}^{*}$ and $\varphi_{i j}^{*}>\varphi_{j j}^{*}$-imposes a limit on relative wages in the two regions. The necessary and sufficient conditions for ensuring that only domestically active firms start exporting are derived in Appendix C.
} 
formulate the conditional export probability as

$$
\left(\frac{\varphi_{i i}^{*}}{\varphi_{i j}^{*}}\right)^{k}=\tau^{-k}\left(\frac{f^{d}+c}{f^{x}-f^{d}}\right)^{\frac{k}{\sigma-1}}\left(\frac{w_{j}}{w_{i}}\right)^{\frac{\sigma k}{\sigma-1}}\left(\frac{\varphi_{i i}^{*}}{\varphi_{j j}^{*}}\right)^{k}
$$

For symmetry, we can infer that the conditional export probability is decreasing in $f^{x}-f^{d}$ and $\tau$ while it is increasing in $f^{d}$ as well as in the agency cost parameter $c$. Further, a higher relative wage in region $j$ reduces that regions competitiveness such that exporting for firms based in region $i$ becomes more likely.

Let us now proceed to the marginal-credit-access condition $(M C A)$. The participation constraint $(P C)$ pins down operating profits of the marginal firm that survives in the domestic market as stated in (6). This allows us to express average profits as a function of domestic cutoff productivity levels. We label this equation the marginal-credit-access condition which is given by 12

$$
\bar{\pi}_{i}=\frac{(1+\rho) w_{i}}{k-\sigma+1}\left\{k c+(\sigma-1)\left[f^{d}+\tau^{-k}\left[\frac{\left(f^{d}+c\right)^{k}}{\left(f^{x}-f^{d}\right)^{k-\sigma+1}}\right]^{\sigma-1}\left(\frac{w_{j}}{w_{i}}\right)^{\frac{\sigma k}{\sigma-1}}\left(\frac{\varphi_{i i}^{*}}{\varphi_{j j}^{*}}\right)^{k}\right]\right\} .
$$

As is evident from $(M C A)$ average profits ceteris paribus increase in $c$. This is because a more severe credit constraint prevents less profitable firms from securing external finance and thus entering the market. Using $(F E)$ and $(M C A)$ for each region delivers two equations that can be solved for the domestic cutoff in $i,{ }^{13}$

$$
\varphi_{i i}^{*}=\left[\frac{\gamma(\sigma-1)}{k-\sigma+1} \frac{1-\phi^{2}}{1-\phi\left(\frac{w_{j}}{w_{i}}\right)^{\frac{\sigma k}{\sigma-1}}}\right]^{\frac{1}{k}},
$$

where we have defined $\gamma \equiv c k /(\sigma-1)+f^{d}$ and $\phi \equiv \tau^{-k}\left(\frac{c+f^{d}}{f^{x}-f^{d}}\right)^{\frac{k-\sigma+1}{\sigma-1}} \frac{\left(c+f^{d}\right)}{\gamma}$. Except for the wage rates, all parameters determining the cutoff productivity are the same for both regions. For symmetric regions, $w_{i}=w_{j}$ and the cutoff is strictly increasing in $c$. This is intuitive as a more severe credit constraint precludes the least productive firms

\footnotetext{
${ }^{12}$ See Appendix A for further details on the derivation of this condition.

${ }^{13}$ Appendix B provides further details on the derivation of the domestic cutoffs and on the comparative statics.
} 
from producing and only the more productive firms remain. Put differently, it requires higher operating profits (which is only possible with a higher $\varphi$ ) to meet $(P C)$. Once regions become asymmetric the cutoffs remain strictly positive in both regions and the region with the higher wage rate features the lower cutoff productivity (see Appendix B and $\mathrm{C}$ for a formal proof). From the participation constraint the latter seems surprising as we would expect more firms to be truncated for higher fixed costs. Yet, there is a countervailing effect which follows from the free-entry condition: Facing higher wages than the foreign region reduces competitiveness and thus average profits which ceteris paribus has to be compensated by a higher probability to survive the lottery, that is by a lower cutoff productivity.

Wages and the number of firms. So far, the discussion was based on a thought experiment with fixed wages. However, both wages and the number of firms in each country, $M_{i}$ and $M_{j}$ adjust endogenously in general equilibrium. Accordingly, to obtain these variables for the general case of an asymmetric allocation of high-skilled workers across regions, we need to employ the respective labor-market-clearing conditions $(L M C)$ jointly with the trade balance equations $(T B)$. Let us denote by $L$ the global stock of low-skilled workers which are distributed symmetrically across both regions such that $L_{i}=L_{j}=L / 2$. The global stock of high-skilled workers is denoted by $H=H_{i}+H_{j}$ and $\lambda$ represents their share residing in region $i$. Expressing the number of exporters and the number of entrants in each region respectively as $M_{i j}=\left(\varphi_{i i}^{*} / \varphi_{i j}^{*}\right)^{k} M_{i}$ and $M_{i e}=$ $\left(\varphi_{i i}^{*}\right)^{k} M_{i} / \psi_{b}$, we can formulate the market-clearing condition for high-skilled workers in region $i$ as ${ }^{14}$

$$
\lambda H=M_{i}\left[\frac{q_{i i}\left(\tilde{\varphi}_{i i}\right)}{\tilde{\varphi}_{i i}}+\frac{f^{d}}{\psi_{b}}\right]+\left(\frac{\varphi_{i i}^{*}}{\varphi_{i j}^{*}}\right)^{k} M_{i}\left[\frac{q_{i j}\left(\tilde{\varphi}_{i j}\right)}{\tilde{\varphi}_{i}}+\frac{f^{x}-f^{d}}{\psi_{b}}\right]+\left(\varphi_{i i}^{*}\right)^{k} \frac{M_{i}}{\psi_{b}} .
$$

Labor demand on the right-hand side of $(L M C)$ has three components. (i) The first component captures variable and fixed labor inputs of all firms in country $i$ that produce for the domestic market plus the fixed inputs of firms that were hit by the bad shock. (ii) The second component refers to the additional labor inputs needed to serve the export market following the same logic. (iii) Finally, some high-skilled workers have chosen to become entrepreneurs which is captured by the last term. A fraction of these entrants is

\footnotetext{
${ }^{14}$ The number of entrants corresponds to the number of workers who want to become an entrepreneur. Only $\varphi_{i i}^{*} \psi_{b}$ of those will eventually become an active entrepreneur.
} 
not productive enough and has never applied for a loan while another fraction has secured external finance but was hit by the bad shock before production started. Both groups end up with no income.

Next, we introduce the trade-balance condition which equates net exports of manufactured varieties with net imports of the homogeneous good. The latter is the difference between local expenditure for the homogeneous good and local production of that good. For region $i$, this can be expressed as $(1-\alpha)\left[L / 2+\lambda H w_{i}\right]-L / 2$ such that the trade-balance condition reads

$$
(1-\alpha) \lambda H w_{i}-\alpha L / 2=\left(\frac{\varphi_{i i}^{*}}{\varphi_{i j}^{*}}\right)^{k} M_{i} r_{i j}\left(\tilde{\varphi}_{i j}\right)-\left(\frac{\varphi_{j j}^{*}}{\varphi_{j i}^{*}}\right)^{k} M_{j} r_{j i}\left(\tilde{\varphi}_{j i}\right) .
$$

The right-hand side represents the difference between aggregate revenues from exports in $i$ and $j$. If production in the manufacturing industry is larger in $i$ than in $j$, region $i$ is a net exporter of manufactured goods and a net importer of the homogeneous good. Note that $(L M C)$ and $(T B)$ are functions of the price index which is given by

$$
P_{i}=\left[M_{i}\left(\frac{\sigma w_{i}}{(\sigma-1) \widetilde{\varphi}_{i i}}\right)^{1-\sigma}+\left(\varphi_{j j}^{*} / \varphi_{j i}^{*}\right)^{k} M_{j}\left(\frac{\tau \sigma w_{j}}{(\sigma-1) \widetilde{\varphi}_{j i}}\right)^{1-\sigma}\right]^{\frac{1}{1-\sigma}}
$$

Similar expressions exist for region $j$ 's labor market and trade balance such that we can use the four equations to solve for $M_{i}, M_{j}, w_{i}$ and $w_{j}$.

\subsection{Endogenous distribution of industry}

We now relax the assumption that high-skilled workers are immobile and allow for an endogenous distribution of manufacturing firms across countries. It is noteworthy that it is not firms that move, but workers. Changing the allocation of labor will result in endogenous adjustments of firms and wages to meet the equilibrium conditions derived in the previous subsection. To describe the long-run equilibrium, we first need to specify the migration equation. High-skilled workers migrate as long as the target region offers higher indirect utility. We compute this value by plugging in the equilibrium outcome of the endogenous variables $M_{i}, M_{j}, w_{i}, w_{j}$ into (3) and calculate the utility differences for the representative mobile laborer in regions $i$ and $j$ for each labor allocation $\lambda$. We identify a migration equilibrium if either (i) indirect utilities of high-skilled workers are equated in 
both regions, so $W_{i}=W_{j}$, or (ii) all workers and industry have agglomerated in one of the two locations. For interior equilibria, we must have

$$
\frac{w_{i}}{P_{i}^{\alpha}}=\frac{w_{j}}{P_{j}^{\alpha}}
$$

Three forces determine the long-run equilibrium. (i) Firms prefer to locate in the larger market as this promises higher profits in the presence of trade costs (Krugman, 1980). This effect is referred to as the home-market effect and works in favor of allocating the manufacturing industry entirely in one region (due to higher nominal wages). (ii) The second effect is called market-crowding effect and works as a dispersion force. The idea is that - for given market size - firms prefer fewer competitors as this increases their market share and hence profits. To meet the labor-market clearing condition, nominal wages need to fall when competition increases. (iii) Finally, the price-index effect states that mobile workers prefer to live in the region with the lower price index. This is usually the larger region as fewer varieties need to be imported and thus, consumer prices are lower. This effect works in favor of agglomeration.

Like in Krugman (1991), endogenous variables enter in a non-linear fashion such that closed-form solutions are generally infeasible. However, we are able to derive closedform solutions for the symmetric equilibrium with $\lambda=0.5$ and corner solutions with $\lambda=1 \vee \lambda=0$. Moreover, we derive an implicit function that describes the critical level of trade costs below which the symmetric equilibrium becomes unstable (break point). For the general case, we solve the model numerically.

Before we study the role of credit constraints for the location of industry, we solve the model in the absence of credit constraints $(c=0)$ for different values of trade costs. This allows us to document that the economic mechanisms in our model produce the same location pattern as in Krugman (1991) - even though he abstracts from heterogeneous firms and export fixed costs. At high levels of trade costs, the symmetric equilibrium with $\lambda=0.5$ is the only stable outcome while corner solutions $(\lambda=1$ or $\lambda=0)$ evolve with low trade barriers. A standard illustration of equilibria in this context is Figure 1 that shows differences in high-skilled workers' indirect utility for each possible labor allocation $\lambda$ and three distinct values of trade costs. ${ }^{15}$ The functions represent equilibria for each level

\footnotetext{
${ }^{15}$ For Figures 1-3 we choose the following parameter values: $f^{x}-f^{d}=35, k=4, \alpha=0.4$, and $\sigma=3$. All the results are insensitive to the choice of these parameters. In choosing the parameter values we account
} 
Figure 1: Trade Costs and Location

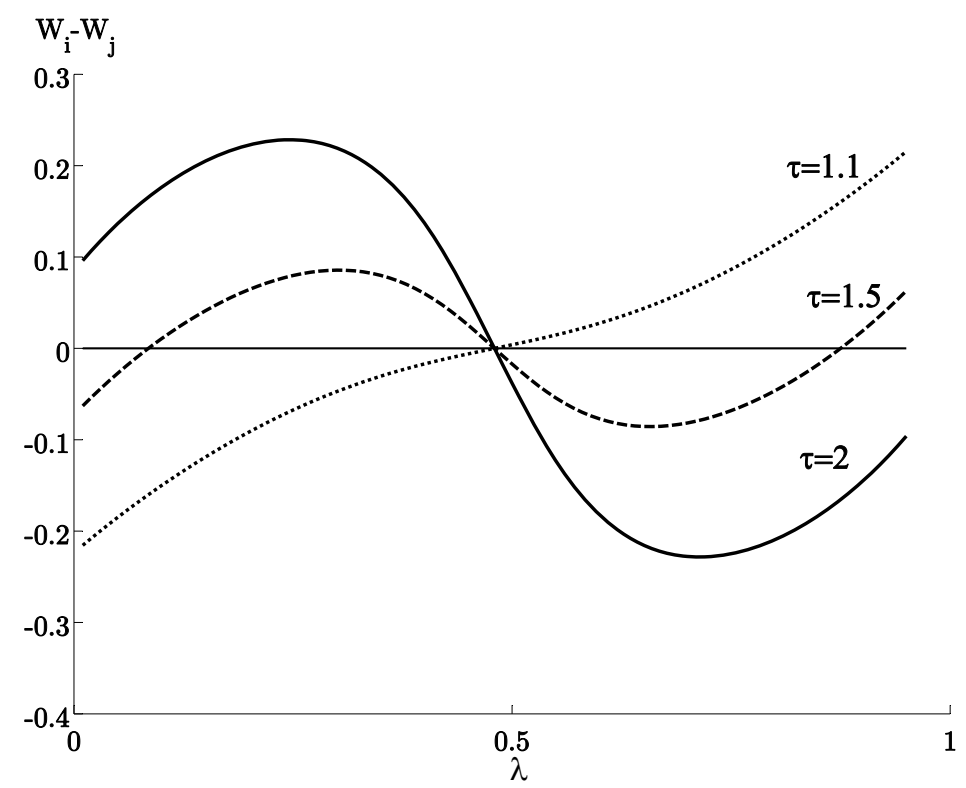

of $\lambda$ when high-skilled workers are assumed to be immobile (short run). If we allow for mobility (long run), though, interior equilibria are only stable if the slope at $W_{i}-W_{j}=0$ is negative. Otherwise, a deviation from the symmetric equilibrium raises indirect utility in the target region inducing more outmigration until all mobile workers reside in one country.

It is apparent that full agglomeration of the manufacturing industry occurs at low levels of trade costs $(\tau=1.1)$. For an intermediate level of trade costs $(\tau=1.5)$, there are five steady states. However, only the full agglomeration equilibria $(\lambda=0$ and $\lambda=1)$ and the symmetric dispersion equilibrium $(\lambda=0.5)$ are stable. Increasing trade frictions to $\tau=2$ renders dispersion forces dominant such that only $\lambda=0.5$ is a stable equilibrium. ${ }^{16}$

for the so called 'no-black-hole' condition $(\sigma-1) / \sigma>\alpha$.

${ }^{16}$ In a recent paper, von Ehrlich and Seidel (2012) show in more detail that firm heterogeneity does not affect the general pattern of industry location in the Krugman (1991) model: Trade liberalization renders clustering of high-skilled workers in one location more attractive. However, firm heterogeneity leads to full agglomeration already at higher levels of trade costs compared to the homogeneous-firms version. 


\section{Financial market development}

\subsection{Location equilibria}

Let us now turn to the role of credit constraints for the equilibrium distribution of mobile workers. For this exercise, we keep trade costs constant (at $\tau=1.7$ ) and vary the agency cost parameter instead. In Figure 2 the solid, dashed, and dotted functions depict the short-run equilibria for the $c=0, c=10$, and $c=20$ scenarios where all other parameters are kept constant. A tightening of credit constraints (an increase in $c$ ) leads to an anti-clockwise rotation of $W_{i}-W_{j}$ around $\lambda=0.5$. Figure 2 helps us identify long-run industry location equilibria. In the absence of credit constraints, that is $c=0$, we observe that only the symmetric interior equilibrium is stable. Full agglomeration is unstable. For an intermediate level of credit constraints, $c=10$, five potential equilibria exist: two asymmetric interior, a symmetric interior and two agglomeration equilibria. In contrast to the symmetric interior and the agglomeration equilibria, the asymmetric interior equilibria are not stable. Raising the financial constraints' intensity further to $c=20$ results in a destabilization of the symmetric equilibrium and implies that asym-

Figure 2: CRedit Constraints And Location

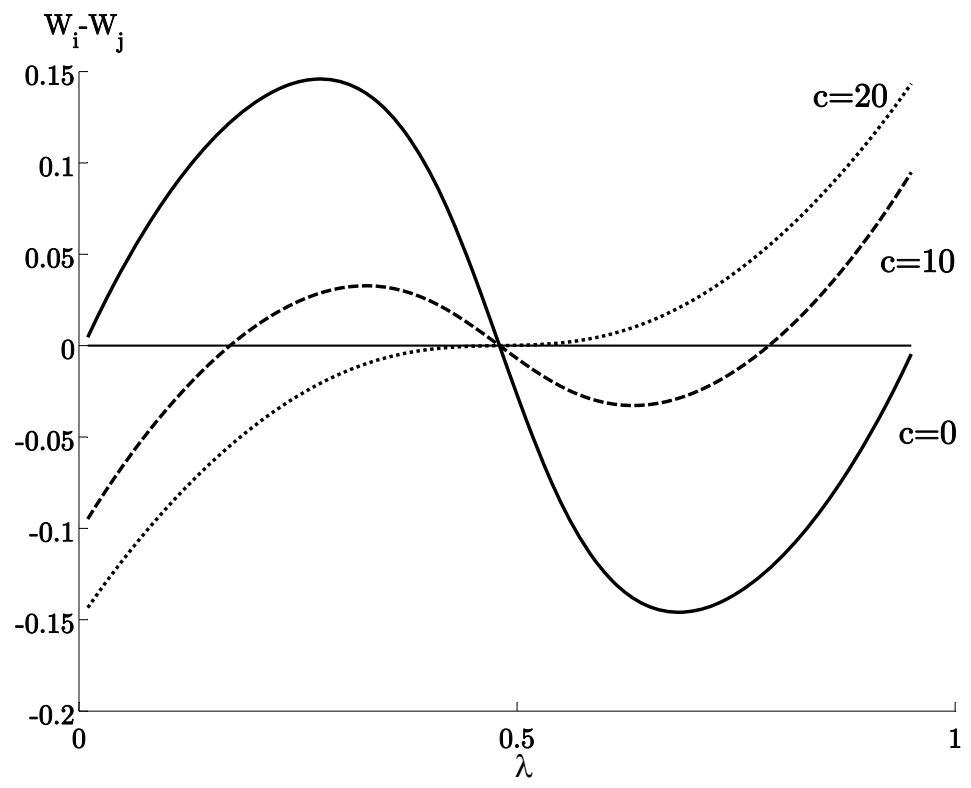


metric interior equilibria no longer exist. Hence, for sufficiently tight credit constraints the entire manufacturing industry is located in one region.

After we have analyzed the effects of credit constraints for a given level of trade costs we now compare long-run location equilibria as a function of trade costs for two distinct levels of credit constraints. We utilize a conventional diagram for summarizing the stability of potential equilibria during a process of falling trade costs, the so-called bifurcation diagram. Figure 3 illustrates the equilibria that may occur at different levels of trade costs in a regime without credit constraints $(c=0)$ compared to a regime with credit constraints $(c=20)$. The solid lines indicate stable equilibria while the dashed lines represent interior asymmetric equilibria which are unstable. It is evident from Figure 3 that stable full-agglomeration equilibria occur at a higher level of trade costs when credit constraints are more severe. Note that an increase in agency costs leads to a marked shift in the break point $\tau_{B}$ - that is the critical level of trade costs below which the symmetric equilibrium is unstable This indicates that net agglomeration forces must increase in $c$ such that credit constraints stimulate the clustering of industries in one location. Or, alternatively, financial market development establishes an equal distribution of economic activity for a wider range of trade costs. In sum, financial market development and trade

Figure 3: LOCATION EQUiLIBRIA

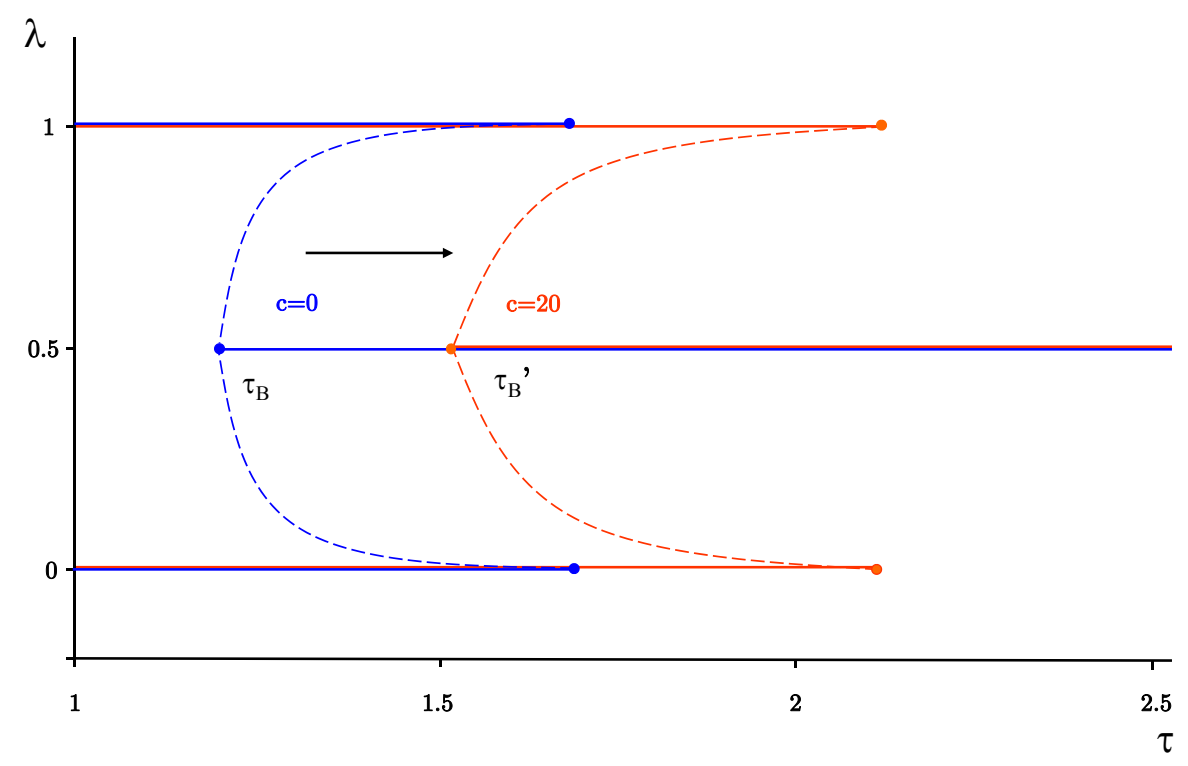


liberalization have opposite effects for the location incentives of mobile factors.

\subsection{Discussion of results}

What is the intuition behind these effects? Why does an increase in credit constraints have a similar impact on the location of industry as a reduction of trade costs? The key to understand the economic mechanism is the propensity to export (8) which is affected by both $\tau$ and $c$. While this result is straightforward for a reduction in trade costs, it is less obvious for credit constraints. If agency costs increase, operating profits have to be higher to convincingly commit to diligent behavior. Otherwise, the lender would not grant the loan. As a consequence, the least productive firms (those with the lowest profits) are denied external finance and have to exit the market. However, exporting firms have no problem in signalling diligent behavior because their profits (from domestic sales and exports) exceed the pledgeable income. ${ }^{17}$ As a consequence, the propensity to export conditional on surviving in competition increases in agency costs. This is easy to show once one considers (8) for a situation with symmetric regions implying $w_{i}=w_{j}$ and $\varphi_{i i}=\varphi_{j j}$. An increase in the export propensity in turn destabilizes the symmetric distribution of workers for reasons we lay out in the following. We

With this insight at hand, we are ready to study the implications for the underlying economic forces that determine the pattern of industry location. For each of these forces, we consider the effect of a marginal change in $\lambda$ around the symmetric equilibrium $\lambda=$ 0.5 and analyze how the effect of a change in $\lambda$ varies with different degrees of credit constraints.

Home-market effect. In the presence of trade costs, a marginal increase in $\lambda$ raises local expenditure and local sales of firms in region $i$. Due to increasing returns this process boosts expected profits in region $i$ such that additional firms are encouraged to enter the industry or the local wage in $i$ has to increase until the free-entry condition is satisfied again. Holding the number of firms constant, the expenditure shift unambiguously raises the local wage rate. An increase in agency costs weakens this effect as it raises the propensity to export according to (8). Hence, firms earn a higher share of their profits from exports rendering the advantage of being close to consumers less important. For higher agency costs, shifting expenditure from region $j$ to $i$ induces a smaller increase

\footnotetext{
${ }^{17}$ We showed this in section 2 .
} 
of domestic sales in $i$ as a higher fraction of this expenditure shift is spent on imports. Hence, the home-market effect is weakened and local wages increase less at higher levels of agency costs. This argument is obviously similar to the effect of lower trade costs on the home-market effect which is intuitive as lower trade costs also increase the propensity to export.

Market-crowding effect. The positive relation between agency costs and export propensity also plays a central role for understanding the role of credit constraints for the marketcrowding effect. The argument becomes most transparent if we consider the boundary case of zero trade costs and an export propensity of one. In this scenario, firm profits would not be affected negatively by more competitors as the degree of competition falls in the foreign market and additional sales in that market fully compensate for reductions in domestic sales. At positive levels of trade costs and export propensities smaller than one, this is no longer the case. Hence, if an increase in agency costs raises the propensity to export, the market-crowding effect becomes necessarily weaker - stimulating location of industry in one region. Again, falling trade costs have a similar effect on this channel.

Price-index effect. Recall that high-skilled workers prefer to live in the region with the lower price index. The price index is lower if more varieties are available for consumption and if the price of the average variety is lower. We identify two effects of an increase in agency costs on the price index. First, higher agency costs increase the export propensity which necessarily raises the share of available varieties in each region. This effect lowers the attractiveness of residing in the larger region because the increase in the exporting propensity is symmetric and thus means a greater absolute increase in the number of varieties available for consumption in the smaller relative to the larger market. Put differently, the disadvantage from not being able to consume a greater fraction of the world's varieties in the smaller region is mitigated after raising the export propensity. Second, higher agency costs lead to fewer and larger firms as the least productive firms are precluded from securing external finance. With fewer varieties available on the market, a marginal change in $\lambda$ implies a smaller difference in the number of varieties produced in each region. Intuitively, this is because the marginal high-skilled worker moving from $j$ to $i$ is less likely to successfully establish a new firm in $i$ for higher agency costs that imply a higher cutoff productivity. Thus, the variety effect also reduces the price-index effect. ${ }^{18}$

\footnotetext{
${ }^{18}$ In line with the literature, note that wages are held constant for the analysis of the price-index effect. This implies that a change in $\lambda$ does not lead to productivity differences across regions. However, both wages and productivities adjust endogenously in general equilibrium and have effects on the price index
} 
Overall effect. To sum up, credit constraints weaken both equalizing and unequalizing forces. However, we have shown that an increase of agency costs has similar implications for the location pattern as trade liberalization since the dispersion force is reduced more than the agglomeration forces. Hence, financial market development and trade liberalization have opposite effects for the location decision of industries. While better access to external finance leads to more dispersion of economic activity across regions, trade liberalization tends to cause clustering of industries.

\subsection{Comparative statics}

To build more confidence in our results, we derive the shift of the break point $\tau_{B}$ induced by an increase in $c$ analytically. In Appendix D we provide the derivations of the closedform solutions for wages, productivities and firm numbers in the symmetric equilibrium. Evaluating the total derivatives of the equilibrium conditions $(L M C)$ and $(T B)$ at the equilibrium values of the endogenous variables for $\lambda=1 / 2$ enables us to express the parameter constellation for which the symmetric equilibrium becomes unstable analytically. This condition (stated in Appendix D) reveals that the break point level of trade costs $\tau_{B}$ depends critically on agency costs $c$, fixed costs $f^{l}$, the underlying productivity distribution $k$, and on the expenditure share of the manufacturing sector $\alpha$. In Figure 4 we illustrate the comparative statics of the break point with respect to these parameters in which we focus on $\tau_{B}(c)$.

In each of the three panels in Figure 4 we plot the break point as a function of the agency cost parameter where the first panel considers different levels of net export fixed costs $f^{x}-f^{d}$, the second panel varies the productivity distribution entrepreneurs draw from, and the third panel highlights the interaction of $\partial \tau_{B} / \partial c$ with the expenditure share of manufacturing products $\alpha$. The $\tau_{B}(c)$ curves display the critical $\tau-c$ combinations where symmetry just starts to become unstable while the areas above and below the individual curves mark $\tau-c$ combinations where symmetry represents a stable and an unstable equilibrium, respectively.

First and most importantly, all panels confirm that the break point $\tau_{B}(c)$ is always increasing in agency costs implying that symmetry is stable for high levels of variable trade costs and low levels of agency costs. This illustrates that (symmetric) financial market de-

as well. See Fujita, Krugman, and Venables (1999) for further discussion. 
Figure 4: Comparative Statics of the Break Point

(i) Change in $f^{x}-f^{d}$

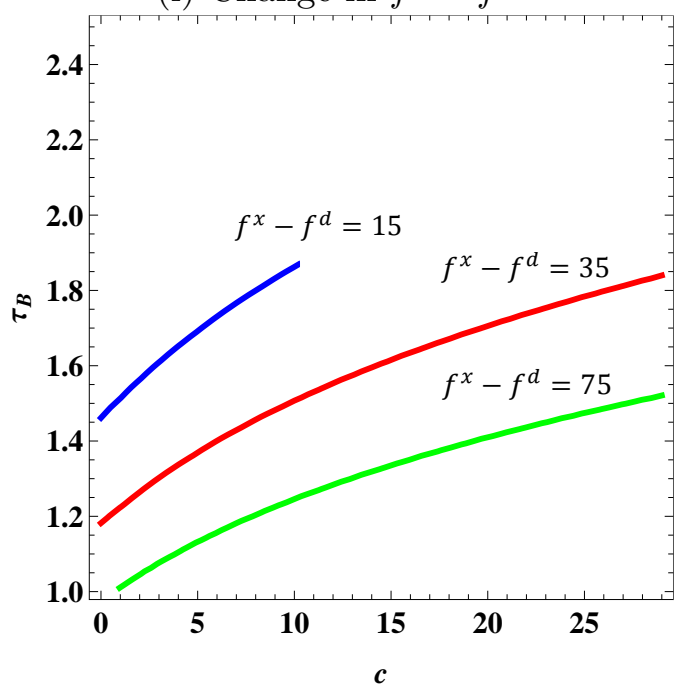

(ii) Change in $k$

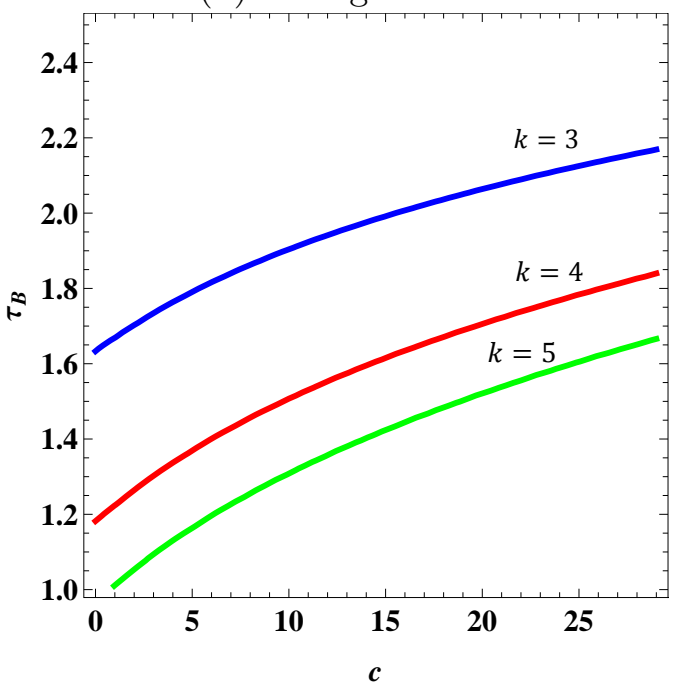

(iii) Change in $\alpha$

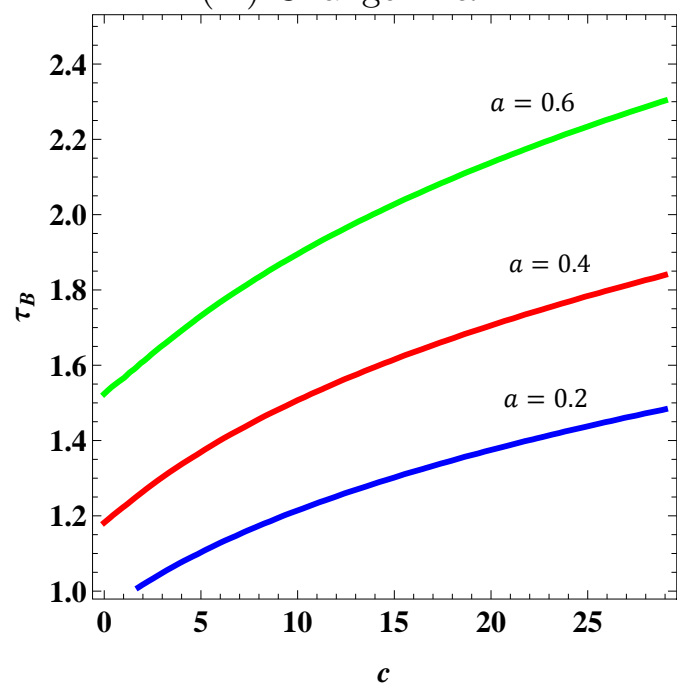

Note: The figures display the break point level of variable trade costs $\tau_{B}$ as a function of agency costs

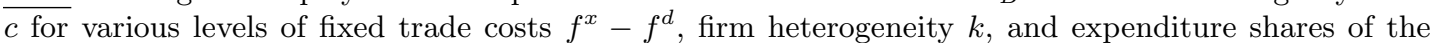
manufacturing sector $\alpha$. The functions follow immediately from (D.5) in Appendix D. In each of the plots, the red line corresponds to a benchmark with $k=4, \sigma=3, f^{x}-f^{d}=35$. The green lines correspond to cases where the change-parameter of the respective panel i.e. $f^{x}-f^{d}, k$, or $\alpha$ is higher than in the benchmark while the blue lines mark cases with lower levels than in the benchmark. Note that the parameter space for $c$ is limited to $c<f^{x}-2 f^{d}$ as we require $\varphi_{j i}^{*}>\varphi_{i i}^{*}$. 
velopment (i.e. a reduction in $c$ ) weakens the incentives for high-skilled workers and industries to cluster in one location while trade liberalization implies the opposite. Turning to panel (i), a higher level of net export fixed costs $f^{x}-f^{d}$ reduces ceteris paribus the symmetry breaking level of variable trade costs. This is intuitive as higher export fixed costs reduce the propensity to export according to (8). As argued above, equalizing forces become relatively stronger implying an equal distribution of the manufacturing industry a stable equilibrium for a wider range of trade costs. Alternatively, this relationship is not surprising as in our model effective trade costs consist of a fixed and a variable component which can substitute for each other. Holding agency costs constant the symmetry breaking indirect utility level can either be reached by a relatively high level of export fixed costs in combination with rather low variable trade costs or by a relatively low level of $f^{x}-f^{d}$ in combination with a high level of $\tau$. In panel (ii), we vary the distribution shape parameter $k$ which is a measure of firm heterogeneity. A high value of $k$ implies a lower probability of drawing a high productivity level $\varphi$ leading to less heterogeneity of firm productivities. We see from (8) that the export propensity declines in $k$ such that symmetry-breaking occurs at lower levels of trade costs. ${ }^{19}$ Lastly, we observe from panel (iii) that a larger expenditure share of the manufacturing sector, $\alpha$, corresponds with stronger net agglomeration forces as the $\tau_{B}(c)$ curve is shifted upwards. This link is well understood in the regional economics literature and also present in our framework. ${ }^{20}$ Intuitively, a low expenditure share reduces the size of the home market $\alpha(L / 2+w \lambda H)$ speaking against clustering. Further, the price index responds less sensitively to changes in the allocation of high-skilled workers if prices of manufactured goods have a low weight in the consumption basket.

\section{$5 \quad$ Empirical evidence}

\section{$5.1 \quad$ Identification and data}

As we have shown above, credit constraints increase the net agglomeration forces because the share of exporters in the total number of active firms rises with higher agency costs. This in turn has a similar impact on the migration equilibrium as a reduction in trade costs and makes agglomeration ceteris paribus a more likely outcome. Accordingly, financial

\footnotetext{
${ }^{19}$ See von Ehrlich and Seidel (2012) for a more detailed exposition of firm heterogeneity for location decisions.

${ }^{20}$ See Baldwin, Forslid, Martin, Ottaviano, and Robert-Nicoud (2003) for details.
} 
markets and the access to external funds should represent a determinant of the distribution of economic activity we observe across countries. In the following, we assess the importance of the link between financial market development and agglomeration by using regional data for eleven industries in 20 European countries.

In order to estimate the effect of financial market development on the agglomeration pattern we build on a popular approach that has been introduced by Rajan and Zingales (1998) to study the role of financial markets for economic growth. They interact indicators of financial development (on the country level) with a measure of external financial dependence of different industries. The identification of causal effects is achieved by exploiting technological reasons for some industries to be more dependent on external finance than others. For instance, the communication sector differs from the pharmaceutical industry with respect to many dimensions that are relevant for the degree of credit financing. Among others, these include the initial project scale, the need for continued investments or the time until returns are realized. Moreover, such industry-specific factors are external to the individual firm and persist across countries. Following Rajan and Zingales, this identification strategy has been used to study numerous aspects of financial market development. For instance, Carlin and Mayer (2003) study differential effects on growth, physical investment, and R\&D investment, Claessens and Laeven (2003) focus on property rights and growth, Manova (2008) applies the approach to international trade, and Maskus, Neumann and Seidel (2012) examine the impact of financial markets on R\&D intensity across industries. Yet, there is no study on the link between financial market development and the spatial concentration of economic activity within countries which corresponds to the hypothesis derived in our theoretical model.

To capture financial market development, we follow the literature in using private credit relative to GDP as provided by the World Bank's Financial Structure Database 2007..$^{21}$ Alternatively, we consider an index on the quality of credit market regulations which stems from Gwartney, Lawson, and Hall (2012). The latter reflects four dimensions of financial market development: the presence of interest rate controls, the competition of foreign bank, the ownership structure of banks, and the level of private sector credit. This index is rescaled to range from 0 to 1 . While the volume of private credit relative to GDP reflects the general availability of credit, our index variable is more closely related to institutional characteristics of financial markets.

\footnotetext{
${ }^{21}$ See Beck, Demirgüç-Kunt, and Levine (2000).
} 
The proxy for industry-specific external financial dependence is computed using balance sheet data for U.S. companies over the time horizon 1980-2012. As in Rajan and Zingales (1998) we resort to Standard and Poor's Compustat database and define a firm's external dependence as capital expenditures minus cash flow from operations divided by capital expenditures. The idea is that higher cash flow makes a firm less dependent on external finance. ${ }^{22}$ We sum the firm's use of external finance over three periods 1980-89, 1990-99, and 2000-2012 before we divide them by the firm's sum of capital expenditures over the respective periods. ${ }^{23}$ Finally, we use the industry median to aggregate the firm level financial external dependence for the 11 industries considered in our study. ${ }^{24}$

We combine the financial data with region-industry specific information on agglomeration pattern. There is a growing literature on how to measure the spatial concentration of economic activity (for a summary see Combes, Mayer, and Thisse, 2008). In the absence of firm data we resort to variants of the Theil index which represent an adequate and intuitive measure of agglomeration. Following Brülhart and Traeger (2005) and Brülhart and Sbergami (2009) we compute the Theil indices for topographic and relative concentration of industry $s$ in country $i$. The index of topographic concentration refers to economic concentration per square kilometer whereas the relative concentration index weights sectoral activity per square kilometer with the total amount of economic activity (over all sectors) on that square kilometer. Hence, the latter takes into account the overall distribution of economic activity and states the concentration of sector $s$ in country $i$ in terms of the concentration of aggregate economic activity. The Theil indices are computed as

$$
T_{i s}=\sum_{j=1}^{N_{i}}\left[\frac{w_{j}}{W_{i}} \frac{y_{j s}}{\bar{y}_{i s}} \log \left(\frac{y_{j s}}{\bar{y}_{i s}}\right)\right],
$$

where $j$ refers to a region within country $i$ such that $j \in\left\{1,2,3, . ., N_{i}\right\}$. We denote by $y_{j s}$ region $j$ 's activity in sector $s$ divided by that regions area and $j$ 's activity in sector $s$ divided by that regions activity over all sectors in the computations of the topographic

\footnotetext{
${ }^{22}$ Precisely, we compute the cash flow as the sum of cash flow from operations, decreases in inventories, decreases in receivables, and increases in payables. For observations where cash flow from operations is missing we replace it by the sum of income before a) extraordinary items, b) funds from operations, c) depreciation and amortization, d) deferred taxes, e) equity in net loss, and f) sale of property, plant and equipment and investments. Our capital expenditures include net acquisitions of fixed assets.

${ }^{23}$ This smoothes the data and reduces the effect of outliers (see also Rajan and Zingales, 1998).

${ }^{24}$ We use the conventional correspondence tables on NACE-ISIC and ISIC-SIC to merge the Compustat data.
} 
and relative indices, respectively. Depending on which index we compute, the weights $w_{j}$ denote area of region $j$ (in case of the topographic index) or total economic activity over all sectors (in case of the relative index). For both indices we define $\bar{y}_{i s}=\sum_{j=1}^{N_{i}} y_{j s}$ and $W_{i}=\sum_{j=1}^{N_{i}} w_{j}$.

We compute these agglomeration indices for 20 European countries and 11 industries over the time period 1980-2012 using NUTS2 ${ }^{25}$ level data from Cambridge Econometrics. ${ }^{26}$ Hence, we compute Theil indices according to (12) for each industry $s$ in each country $i$ and in each year $t$, i.e. we have dependent variables $T_{i s t}$. Agglomeration in terms of our theoretical model refer to employment in the manufacturing sector. Therefore, we chose to measure economic activity $y_{j s t}$ in terms of employment in NUTS2 region $j$ and industry $s$. For sensitivity we consider the gross value added (GVA) as an alternative measure of economic activity such that we have in total four different measures of agglomeration: Topographic and relative concentration indices for economic activity in terms of employment and gross value added. Our industry classification is adopted from Cambridge Econometrics and bases on the NACE classification. ${ }^{27}$ Summary statistics for our agglomeration indices, the external financial dependence variable, and the measure of financial market development are provided in Table 1.

The reduced-form model we estimate captures time-invariant country and industry characteristics denoted by $\eta_{i}$ and $\eta_{s}$, respectively. Moreover, we include time dummies $\eta_{t}$ to absorb all common shocks countries and industries face and our estimation equation is given by:

$$
T_{i s t}=\alpha+\beta\left(\text { Ext.Fin.Dep } p_{s t} \times \text { Fin.Devit }\right)+\eta_{t}+\eta_{i}+\eta_{s}+u_{i s t},
$$

\footnotetext{
${ }^{25}$ NUTS is the acronym for $N$ omenclature des $U$ nités Territoriales $S$ tatistiques coined by Eurostat, the Statistical Office of the EU, which refers to regional aggregates. NUTS2 regions correspond to groups of counties and unitary authorities with a population of 0.8-3 million inhabitants.

${ }^{26}$ The countries include Austria, Belgium, Bulgaria, Switzerland, Czech Republic, Germany, Spain, Finland, France, Greece, Hungary, Italy, Netherlands, Norway, Poland, Portugal, Romania, Sweden, Slovak Republic, United Kingdom. We drop countries comprising less than 4 NUTS2 regions, this is Denmark, Ireland, and Luxembourg. For Bulgaria, Czech Republic, Hungary, Poland, and Romania we use only data from 1991 onwards.

${ }^{27}$ We cover the following industries: Food, beverages and tobacco; Textiles and leather etc.; Electrical and optical equipment; Transport equipment; Other manufacturing; Construction; Distribution; Hotels and restaurants; Transport, storage and communications; Real estate, renting and business activities; Coke, refined petroleum, nuclear fuel and chemicals etc.. We drop the agricultural sector, the financial sector, and the public sector because location decisions in these sectors are typically not affected by the mechanism we highlight in the theoretical part of this paper.
} 
where $u_{i s t}$ represents the error-term and $\beta$ represents the effect of interest. After controlling for country-, industry- and year-specific effects, our measure of external financial dependence Ext.Fin.Depst reflects time-specific within-country differences across industries. Interacting this information with our measure for country-specific development in financial markets Fin.Dev $i$ allows us to identify the effect of financial market development on agglomeration. We use private credit relative to GDP Credit/GDP and the indicator on the quality of credit market regulations $C M R$ as alternative measures for financial market development Fin.Dev $i t \in\left\{\right.$ Credit $\left./ G D P_{i t}, C M R_{i t}\right\}$.

Table 1: Descriptive Statistics

\begin{tabular}{lccrrr} 
& Mean & Std. Dev. & Min & Max & Obs. \\
\cline { 2 - 6 } & $(1)$ & $(2)$ & $(3)$ & $(4)$ & $(5)$ \\
\hline$T^{\text {Topo }}($ Empl $)$ & 0.555 & 0.384 & 0.006 & 3.534 & 5,192 \\
$T^{\text {Topo }}(G V A)$ & 0.588 & 0.318 & 0.0148 & 2.037 & 5,192 \\
$T^{\text {Rel }}($ Empl $)$ & 0.071 & 0.107 & 0.0002 & 1.220 & 5,192 \\
$T^{\text {Rel }}(G V A)$ & 0.064 & 0.084 & 0.0004 & 0.681 & 5,192 \\
Credit/GDP & 0.721 & 0.396 & 0.064 & 2.178 & 5,192 \\
CMR & 0.805 & 0.160 & 0.040 & 1 & 5,192 \\
Ext.Fin.Dep & 0.489 & 0.636 & -0.083 & 3.548 & 5,192 \\
\hline \hline
\end{tabular}

Notes: Units of observation are industries in NUTS2 regions across 20 EU countries and 30 years 1980-2009. GVA and Employment data are from Cambridge Econometrics; information about Credit/GDP is from the World Bank's Financial Structure Database 2007, the data for CMR stems from Gwartney, Lawson, and Hall (2012), and Ext.Fin.Dep is computed from the Standard and Poor's Compustat database following the procedure introduced by Rajan and Zingales (1998). $T^{\text {Topo }}(E m p l)$ and $T^{R e l}(G V A)$ refer to the topographic Theil index using industryNUTS2 region employment and to the relative Theil index using industry-NUTS2 region value added, respectively. In total we have 11 industries, 20 countries and 30 years which yields 6,600 observations in total. We lose 1,408 observations due to missing data in Credit/GDP, in Employment, and in $G V A$. These particularly Central Eastern European countries for which we have data only from the 1990s onwards.

Unobserved information might raise concerns about endogeneity and causality of the effect we identify in (13). For instance, deeper economic integration might have led to contemporaneous trends towards more agglomeration and deeper financial markets. Yet, there are several arguments in favor of our specification. First, a common trend would generally be absorbed by $\eta_{t}$. Second, to render our results invalid omitted information would have to drive country-specific development of financial markets and industry-specific determinants of external financial dependence at the same time. Third, our measure of external financial dependence does not vary over countries and is computed from ten year 
averages using U.S. data. Thus, annual changes in European agglomeration patterns are not likely to have a causal effect on our measure of external dependence computed for the corresponding U.S industries.

\subsection{Findings}

The results of our estimations are presented in Table 2 which consists of two panels: panel A and B reporting the specifications with topographic and relative agglomeration indices as dependent variables, respectively. In both panels, the first two columns refer to agglomeration in terms of employment while columns three and four refer to spatial concentration of economic activity in terms of gross value added. In all specifications but for the relative Theil index of GVA we find a significant and negative effect of financial development on the degree of agglomeration. This result holds true irrespective of whether we consider Credit/GDP or $C M R$ as a measure of financial development. Moreover, the effect tends to be more pronounced for topographic agglomeration than for relative agglomeration (both in terms of significance and magnitude). Accordingly, the effect of financial markets on agglomeration relative to physical space is stronger than the effect on agglomeration relative to the total distribution of employment. ${ }^{28}$ Overall, our empirical analysis provides robust evidence for the negative relationship between financial market development and agglomeration intensity that is highlighted in our theoretical model.

The interpretation of the coefficients is not straightforward for interacted continuous variables. To get an idea of the magnitude consider the following thought experiment which builds on a quartile comparison: We compute the difference in the agglomeration intensity between the sectors at the $75^{\text {th }}$ and $25^{t h}$ percentile of Ext.Fin.Dep.. Then we move both sectors from a country with low financial market development $\left(25^{\text {th }}\right.$ percentile of $C r e d i t / G D P)$ to a country with high financial market development $\left(75^{\text {th }}\right.$ percentile of $C$ redit/GDP). The coefficient for topographic agglomeration in terms of employment then predicts that the agglomeration difference between the two industries with different levels of dependence on external funds decreases by about 0.7 standard deviations due to the increase in financial market development. This is because the degree of agglomeration drops more rapidly in the industry that relies heavily on external funds than in the less dependent industry. We compute the corresponding agglomeration differentials for all

\footnotetext{
${ }^{28}$ Note also that these results are robust to the inclusion of industry shares in terms of GVA or employment on the country level.
} 
Table 2: Financial Market Development and Agglomeration

Employment

(1) (2) $\quad$ GVA

\section{A. Topographic Concentration}

Ext.Fin.Dep. $\times$ Credit/GDP $-.017$

$-.010$

$(.004)^{* * *}$

$(.005)^{* *}$

Ext.Fin.Dep. $\times$ CMR

Const.

.292
$(.025)^{* * *}$

$-.002$ $(.0005)^{* * *}$

$-.001$

.306

$(.024)^{* * *}$

$(.022)^{* * *}$

$(.0006)^{* *}$

.424

$(.021)^{* * *}$

includes country-, sector-, and time- fixed effects

\begin{tabular}{lcccc} 
Differential in Agglomeration & -0.696 & -0.031 & -0.494 & -0.019 \\
Obs. & 5,192 & 5,192 & 5,192 & 5,192 \\
$R^{2}$ & .727 & .727 & .702 & .702 \\
\hline
\end{tabular}

\section{B. Relative Concentration}

Ext.Fin.Dep. $\times$ Credit/GDP

$$
\begin{gathered}
-.004 \\
(.002)^{* * *}
\end{gathered}
$$

.002

Ext.Fin.Dep. $\times$ CMR

.039
$(.009)^{* * *}$

Const.

-.008
$(.002)^{* * *}$
.038
$(.009)^{* * *}$

includes country-, sector-, and time- fixed effects

\begin{tabular}{lcccc} 
Differential in Agglomeration & -0.586 & -0.441 & - & - \\
& & & & 5,192 \\
Obs. & 5,192 & 5,192 & .429 & .429 \\
$R^{2}$ & .448 & .449 & .492 \\
\hline \hline
\end{tabular}

Notes: ${ }^{* * *},{ }^{* *},{ }^{*}$ denote statistical significance at the $1 \%, 5 \%$, and $10 \%$ level, respectively. All standard errors are robust against heteroskedasticity. All results are robust to the inclusion of country level data on industry shares (measured in terms of gross value added or employment). The agglomeration differential refers to a quartile comparison: we compute the predicted agglomeration difference if we moved sectors at $75^{t h}$ and $25^{t h}$ percentile of Ext.Fin.Dep. from a country with low financial development $\left(25^{\text {th }}\right.$ of Credit/GDP or CMR) to country with high financial development ( $75^{t h}$ of Credit/GDP or CMR). The difference we predict for this experiment is then expressed in terms of a std. dev. of the respective dependent variable. 
agglomeration indices and for both measures of financial market development and report them in Table 2.

We acknowledge that our reduced-form empirical specification is not capable of determining whether the identified effect is driven by a selection mechanism as it is underlying our theoretical model. Yet, our empirical findings are consistent with the predictions of the theoretical model and they provide robust evidence for the development of financial markets to play a decisive role for agglomeration.

\section{Concluding remarks}

In this paper, we have developed a model that combines goods trade, labor migration and credit constraints due to moral hazard to study the role of financial market development for the distribution of economic activity across regions. We show that better access to external funds reduces the incentives for high-skilled workers to cluster in one region such that economic activity and thus wealth is more equally distributed. This result stands in contrast to previous research in the finance literature where globalization of financial markets was shown to cause more inequality.

In our framework, the effects of financial market development work through integrated product markets. Mitigating credit constraints reduces the export propensity such that clustering of all firms in one location becomes less attractive. An increase of trade barriers would have the same effects (which is well understood). The export decision is not subject to moral hazard because only very productive, and thus large firms find it profitable to serve customers abroad. Given that these firms also make large profits from domestic sales, their managers have no problem in committing to diligent behavior to secure the loan. In this case, diligent behavior implies a strictly higher income for entrepreneurs.

Using comprehensive data on the clustering of industries in Europe over the last 30 years we provide evidence in favor of the negative relationship between financial market development and clustering of industries. Moreover, the response to a deepening of financial markets is more pronounced for industries that depend heavily on external finance than for industries that are less dependent on external credit. This shows that financial markets - which have been largely ignored in the literature - should be considered as a crucial determinant of industry location. 
Our results have important implications for public policies. As politicians are often concerned about regional cohesion, it is crucial to understand the implications of financial market development for the location pattern of industries. In this regard, our paper conveys good news in the sense that lower financial frictions work as a countervailing force to trade integration in reducing the incentive for clustering. 


\section{Appendix}

\section{A Deriving the marginal-credit-access condition (MCA)}

Average expected profits accrue from domestic operating profits $r_{i i}\left(\widetilde{\varphi}_{i i}\right) / \sigma$ minus fixed costs for domestic sales and from foreign operating profits $r_{i j}\left(\widetilde{\varphi}_{i j}\right) / \sigma$ minus export fixed costs. The latter have to be weighted by the probability of becoming an exporter conditional on being active in the domestic market. Hence, the average expected profits in region $i$ read

$$
\bar{\pi}_{i}=\frac{r_{i i}\left(\widetilde{\varphi}_{i i}\right)}{\sigma}-f^{d} w_{i}(1+\rho)+\left(\frac{\varphi_{i i}^{*}}{\varphi_{i j}^{*}}\right)^{k}\left[\frac{r_{i j}\left(\widetilde{\varphi}_{i j}\right)}{\sigma}-\left(f^{x}-f^{d}\right) w_{i}(1+\rho)\right] .
$$

Substituting $r_{i i}\left(\widetilde{\varphi}_{i i}\right)=\left(\frac{\widetilde{\varphi}_{i i}}{\varphi_{i i}^{*}}\right)^{\sigma-1} r_{i i}\left(\varphi_{i i}^{*}\right)$ and $r_{i j}\left(\widetilde{\varphi}_{i j}\right)=\left(\frac{\widetilde{\varphi}_{i j}}{\varphi_{i j}^{*}}\right)^{\sigma-1} r_{i j}\left(\varphi_{i j}^{*}\right)$ - which holds because revenues from the respective market differ only with respect to firm-specific productivity - as well as $r_{i i}\left(\varphi_{i i}^{*}\right)=\sigma w_{i}\left[\frac{f^{d}}{\psi_{b}}+\frac{B}{\Delta \psi}\right]$ and $r\left(\varphi_{i j}^{*}\right)=\sigma w_{i} \frac{f^{x}-f^{d}}{\psi_{b}}$ from equations (5) and (6) yields

$\bar{\pi}_{i}=\left[\left(\frac{\widetilde{\varphi}_{i i}}{\varphi_{i i}^{*}}\right)^{\sigma-1}\left(f^{d}+c\right)-f^{d}\right] w_{i}(1+\rho)+\left(\frac{\varphi_{i i}^{*}}{\varphi_{i j}^{*}}\right)^{k}\left[\left(\frac{\widetilde{\varphi}_{i j}}{\varphi_{i j}^{*}}\right)^{\sigma-1}-1\right]\left(f^{x}-f^{d}\right) w_{i}(1+\rho)$.

Note that we have substituted $\psi_{b}=1 /(1+\rho)$ and $c=B /[\Delta \psi(1+\rho)]$. Further substituting the Pareto distribution's characteristics $\widetilde{\varphi}_{i i} / \varphi_{i i}^{*}=\widetilde{\varphi}_{i j} / \varphi_{i j}^{*}=[k /(k-\sigma+1)]^{1 /(\sigma-1)}$, as well as the export probability from equation (8) delivers the average expected profits as stated in equation $(M C A)$.

\section{B Deriving the domestic cutoffs}

Using the marginal-credit-access conditions $(M C A)$ together with the free-entry conditions $(F E)$ yields

$$
\begin{aligned}
& \frac{k-\sigma+1}{\sigma-1}=\left(\varphi_{i i}^{*}\right)^{-k}\left(\frac{c k}{\sigma-1}+f^{d}\right)+\left(\varphi_{j j}^{*}\right)^{-k} \tau^{-k}\left(f^{x}-f^{d}\right)^{\frac{k-\sigma+1}{1-\sigma}}\left(\frac{w_{j}}{w_{i}}\right)^{\frac{\sigma k}{\sigma-1}}\left(f^{d}+c\right)^{\frac{k}{\sigma-1}} \\
& \frac{k-\sigma+1}{\sigma-1}=\left(\varphi_{j j}^{*}\right)^{-k}\left(\frac{c k}{\sigma-1}+f^{d}\right)+\left(\varphi_{i i}^{*}\right)^{-k} \tau^{-k}\left(f^{x}-f^{d}\right)^{\frac{k-\sigma+1}{1-\sigma}}\left(\frac{w_{i}}{w_{j}}\right)^{\frac{\sigma k}{\sigma-1}}\left(f^{d}+c\right)^{\frac{k}{\sigma-1}}
\end{aligned}
$$


for countries $i$ and $j$, respectively. This equation system can be solved for the domestic cutoffs in the two countries:

$$
\begin{gathered}
\left(\varphi_{i i}^{*}\right)^{k}=\frac{\sigma-1}{k-\sigma+1} \frac{\left(\frac{c k}{\sigma-1}+f^{d}\right)^{2}-\left[\tau^{-k}\left(f^{x}-f^{d}\right)^{\frac{k-\sigma+1}{1-\sigma}}\left(f^{d}+c\right)^{\frac{k}{\sigma-1}}\right]^{2}}{\frac{c k}{\sigma-1}+f^{d}-\tau^{-k}\left(f^{x}-f^{d}\right)^{\frac{k-\sigma+1}{1-\sigma}}\left(\frac{w_{j}}{w_{i}}\right)^{\frac{\sigma k}{\sigma-1}}\left(f^{d}+c\right)^{\frac{k}{\sigma-1}}} \\
\left(\varphi_{j j}^{*}\right)^{k}=\frac{\sigma-1}{k-\sigma+1} \frac{\left(\frac{c k}{\sigma-1}+f^{d}\right)^{2}-\left[\tau^{-k}\left(f^{x}-f^{d}\right)^{\frac{k-\sigma+1}{1-\sigma}}\left(f^{d}+c\right)^{\frac{k}{\sigma-1}}\right]^{2}}{\sigma-1}+f^{d}-\tau^{-k}\left(f^{x}-f^{d}\right)^{\frac{k-\sigma+1}{1-\sigma}}\left(\frac{w_{i}}{w_{j}}\right)^{\frac{\sigma k}{\sigma-1}}\left(f^{d}+c\right)^{\frac{k}{\sigma-1}}
\end{gathered}
$$

Substituting $\gamma=c k /(\sigma-1)+f^{d}$ and $\phi \equiv \tau^{-k}\left(\frac{c+f^{d}}{f^{x}-f^{d}}\right)^{\frac{k-\sigma+1}{\sigma-1}} \frac{\left(c+f^{d}\right)}{\gamma}$ delivers equation (B.1):

$$
\varphi_{i i}^{*}=\left[\frac{\gamma(\sigma-1)}{k-\sigma+1} \frac{1-\phi^{2}}{1-\phi\left(\frac{w_{j}}{w_{i}}\right)^{\frac{\sigma k}{\sigma-1}}}\right]^{\frac{1}{k}}
$$

Since $\frac{\gamma(\sigma-1)}{k-\sigma+1}>0$ the cutoffs are strictly positive as long as $\phi<1$ and $\frac{1}{\phi}>\left(\frac{w_{j}}{w_{i}}\right)^{\frac{\sigma k}{\sigma-1}}$. Under the parameter restrictions $k>\sigma-1$ and $c<f^{x}-2 f^{d}$ it can easily be shown that $\phi<1$ holds true. Moreover, assuming that only domestically active firms operate on the export market requires $\frac{1}{\phi}>\left(\frac{w_{i}}{w_{j}}\right)^{\frac{\sigma k}{\sigma-1}}$ as will be proven in Appendix C below. For symmetric countries, i.e. $w_{i}=w_{j}$, it can easily be shown that the cutoffs are strictly increasing in $c$ if $\frac{\partial \phi}{\partial c}>0$ which holds true for $k>\sigma-1$. For asymmetric countries the effect of $c$ on the cutoffs cannot be determined without taking into account the impact of $c$ on the relative wages $w_{j} / w_{i}$. This, however, cannot be done analytically, but requires to solve the model numerically.

\section{Ensuring that only domestically active firms start exporting}

It is a common assumption of the heterogenous-firms literature and in line with empirical evidence, that exporting firms also serve the domestic market. This is equivalent to requiring $\varphi_{i j}^{*}>\varphi_{i i}^{*}$ and $\varphi_{j i}^{*}>\varphi_{j j}^{*}$ which at the same time ensures that the conditional export probability ranges between zero and unity. In our framework, these assumptions are reflected by the following constraints in the symmetric and asymmetric case: 
1. For symmetric countries, $w_{i}=w_{j}$ and $\varphi_{i i}^{*}=\varphi_{j j}^{*}$, and the export cutoffs of the two countries can be stated as functions of the domestic cutoffs (see Section 3):

$$
\varphi_{i j}^{*}=\tau\left(\frac{f^{x}-f^{d}}{f^{d}+c}\right)^{\frac{1}{\sigma-1}} \varphi_{j j}^{*} \quad \varphi_{j i}^{*}=\tau\left(\frac{f^{x}-f^{d}}{f^{d}+c}\right)^{\frac{1}{\sigma-1}} \varphi_{i i}^{*} .
$$

Accordingly, for symmetric countries and trade costs converging to unity the export cutoffs are greater than their domestic counterparts as long as $f^{x}-f^{d}>f^{d}+c$ is satisfied. Since $c \geq 0$ this requires that the additional costs for becoming an exporter firm exceed the fixed costs for setting up a domestic firm $f^{x}-f^{d}>f^{d}$.

2. For asymmetric countries, ensuring that only domestically active firm export restricts the support region of $w_{i}$ and $w_{j}$ to

$$
\begin{gathered}
\frac{w_{i}}{w_{j}}<\left(\frac{f^{x}-f^{d}}{\phi \gamma}\right)^{\frac{\sigma-1}{\sigma k}} \wedge \frac{w_{j}}{w_{i}}<\left(\frac{f^{x}-f^{d}}{\phi \gamma}\right)^{\frac{\sigma-1}{\sigma k}} \\
\text { or } \\
\frac{w_{i}}{w_{j}}<\left(\frac{1}{\phi}\right)^{\frac{\sigma-1}{\sigma k}} \wedge \frac{w_{j}}{w_{i}}<\left(\frac{1}{\phi}\right)^{\frac{\sigma-1}{\sigma k}}
\end{gathered}
$$

where $\gamma \equiv c k /(\sigma-1)+f^{d}$ and $\phi \equiv \tau^{-k}\left(\frac{c+f^{d}}{f^{x}-f^{d}}\right)^{\frac{k-\sigma+1}{\sigma-1}} \frac{\left(c+f^{d}\right)}{\gamma}$. Note that $f^{x}-f^{d} \lesseqgtr \gamma$ depending on whether $c k /(\sigma-1) \lesseqgtr f^{x}-2 f^{d}$. In our general setting, we allow for parameter constellations that render either the first constraint (in case $\left.c k /(\sigma-1)>f^{x}-2 f^{d}\right)$ or the second constraint binding (in case $\left.c k /(\sigma-1)<f^{x}-2 f^{d}\right)$. In both situations the applicable constraint constitutes a necessary and sufficient condition for $\varphi_{i j}^{*}>\varphi_{i i}^{*}$ and $\varphi_{j j}^{*}>\varphi_{j i}^{*}$ as will be shown in the following.

Think of a situation where $w_{i}>w_{j}>0$, and $\frac{w_{i}}{w_{j}}>\left(\frac{1}{\phi}\right)^{\frac{\sigma-1}{\sigma k}}$. This implies that the domestic cutoff in $j\left(\varphi_{j j}^{*}\right)$ as derived in Appendix B is negative while the domestic cutoff in $i\left(\varphi_{i i}^{*}\right)$ is positive. Recall that $f^{x}-f^{d}>0$, such that $\varphi_{i i}^{*}>0$ and $\varphi_{j j}^{*}<0$ imply from equation (7) that the export cutoff in $j\left(\varphi_{j i}^{*}\right)$ is positive and the export cutoff in $i$ $\left(\varphi_{i j}^{*}\right)$ is negative. Hence, under the assumptions that $w_{i}>w_{j}>0$ and $\frac{w_{i}}{w_{j}}>\left(\frac{1}{\phi}\right)^{\frac{\sigma-1}{\sigma k}}$ the ordering of domestic and export cutoffs in region $i$ is $\varphi_{i j}^{*}<\varphi_{i i}^{*}$ which means that there are some firms in $i$ that export, but do not produce for the domestic market. Similarly, assuming $w_{j}>w_{i}>0$ and $\frac{w_{j}}{w_{i}}>\left(\frac{1}{\phi}\right)^{\frac{\sigma-1}{\sigma k}}$ yields $\varphi_{j i}^{*}<\varphi_{j j}^{*}$ such that some firms in $j$ 
produce for the export market only. Accordingly, a necessary assumption for precluding firms in both regions from exporting without producing for the domestic market is $\frac{w_{i}}{w_{j}}<$ $\left(\frac{1}{\phi}\right)^{\frac{\sigma-1}{\sigma k}} \wedge \frac{w_{j}}{w_{i}}<\left(\frac{1}{\phi}\right)^{\frac{\sigma-1}{\sigma k}}$ which ensures that $\varphi_{i j}^{*}$ and $\varphi_{j i}^{*}$ are positive. However, if $f^{x}-f^{d}<\gamma$ this condition may not be sufficient as there could be solutions where all cutoff productivities are positive but $\varphi_{i j}^{*}<\varphi_{i i}^{*}$ or $\varphi_{j i}^{*}<\varphi_{j j}^{*}$ still applies. From equations (7) we observe that $\frac{w_{i}}{w_{j}}<\left(\frac{f^{x}-f^{d}}{\phi \gamma}\right)^{\frac{\sigma-1}{\sigma k}} \wedge \frac{w_{j}}{w_{i}}<\left(\frac{f^{x}-f^{d}}{\phi \gamma}\right)^{\frac{\sigma-1}{\sigma k}}$ has to be fulfilled in such a scenario in order to guarantee $\varphi_{i j}^{*}>\varphi_{i i}^{*}$ and $\varphi_{j i}^{*}>\varphi_{j j}^{*}$.

Together, the two constraints on relative wages from above constitute sufficient conditions for ensuring that only domestic producers become exporters. Again, consider a situation where $w_{i}>w_{j}$, but let the relative wage constraints in (C.1) be satisfied for now. Then from the domestic-cutoff equation (B.1), both $\varphi_{i i}^{*}$ and $\varphi_{j j}^{*}$ are strictly positive. Taking a closer look at equation (B.1) reveals that - under the above assumptions $\left(\frac{1}{\phi}\right)^{\frac{\sigma-1}{\sigma k}}>\frac{w_{i}}{w_{j}}$, and $\left(\frac{1}{\phi}\right)^{\frac{\sigma-1}{\sigma k}}>\frac{w_{j}}{w_{i}}-$ the country with the higher wage rate features the lower domestic cutoff productivity. That is $\varphi_{j j}^{*}>\varphi_{i i}^{*}$ for $w_{i}>w_{j}$ which under the constraints $\frac{w_{i}}{w_{j}}<\left(\frac{f^{x}-f^{d}}{\phi \gamma}\right)^{\frac{\sigma-1}{\sigma k}} \wedge \frac{w_{j}}{w_{i}}<\left(\frac{f^{x}-f^{d}}{\phi \gamma}\right)^{\frac{\sigma-1}{\sigma k}}$ implies from equation (7) that $\varphi_{i j}^{*}>\varphi_{j i}^{*}$, $\varphi_{i j}^{*}>\varphi_{i i}^{*}$, and $\varphi_{j i}^{*}>\varphi_{j j}^{*}$ hold true. Therefore, the overall productivity ordering for the $w_{i}>w_{j}$ scenario is $\varphi_{i j}^{*}>\varphi_{j i}^{*}>\varphi_{j j}^{*}>\varphi_{i i}^{*}>0$. Similarly, the $w_{j}>w_{i}$ scenario yields $\varphi_{j i}^{*}>\varphi_{i j}^{*}>\varphi_{i i}^{*}>\varphi_{j j}^{*}>0$ under the relative wage constraints.

\section{Deriving the symmetric equilibrium and the break point}

At $\lambda=1 / 2$ it holds true that $d W_{i}=-d W_{j}$. Therefore, it follows that the symmetric equilibrium is stable as long as an additional worker in $i$ decreases real wages in $i$ - which corresponds to an increase of real wages in $j$ and a negative real wage differential $W_{i}-W_{j}$. Hence, the break point is characterized by the level of trade costs that satisfies:

$$
\left.\frac{d W_{i}}{d \lambda}\right|_{\lambda=1 / 2}=0 \quad \Leftrightarrow \quad d w_{i}=\alpha w_{i} \frac{d P_{i}}{P_{i}} \text { for } \lambda=1 / 2
$$

Solving for the break point involves tedious algebra. First, we totally differentiate the labor market clearing condition $(L M C)$ and trade balance condition $(T B)$. Second, we use this equation system to compute the total derivatives of the price index, the total derivative of the wage rate, and the total derivative of the number of firms (which is part 
of the price index). Second, we determine the equilibrium values of $w_{i}, P_{i}$, and $M_{i}$ at $\lambda=1 / 2$ and evaluate the above mentioned total derivatives at the symmetric equilibrium.

At the symmetric equilibrium, it can easily be shown from the trade balance condition $(T B)$ that the wage is given by $w_{i}=\frac{\alpha L}{(1-\alpha) H_{i}}$. To simplify computation we follow most of the literature and normalize the total number of low-skilled workers to $L=1-\alpha$ and the total number of high-skilled workers to $H_{i}+H_{j}=\alpha$. This implies that the high-skilled wage under symmetry is unity. With $\lambda=1 / 2, w_{i}=w_{j}=1$, and $M_{i}=M_{j}$, the price index from (10) can be simplified to:

$$
\begin{aligned}
P_{i} & =M_{i i}^{\frac{1}{1-\sigma}}\left[\left(\frac{\sigma w_{i}}{(\sigma-1) \widetilde{\varphi}_{i i}}\right)^{1-\sigma}+\left(\varphi_{j j}^{*} / \varphi_{j i}^{*}\right)^{k}\left(\frac{\tau \sigma w_{j}}{(\sigma-1) \widetilde{\varphi}_{j i}}\right)^{1-\sigma}\right]^{\frac{1}{1-\sigma}} \\
& =M_{i i}^{\frac{1}{1-\sigma}} \frac{\sigma}{(\sigma-1)}\left(\frac{k}{k-\sigma+1}\right)^{\frac{1}{1-\sigma}}\left(\frac{k-\sigma+1}{\gamma(\sigma-1)(1+\phi)}\right)^{\frac{1}{k}}\left[1+\phi\left(f^{d}+c\right) \gamma\right],
\end{aligned}
$$

where $\gamma=\frac{c k}{\sigma-1}+f^{d}$ and $\phi=\tau^{-k}\left(\frac{c+f^{d}}{f^{x}-f^{d}}\right)^{\frac{k-\sigma+1}{\sigma-1}} \frac{\left(c+f^{d}\right)}{\gamma}$. Using the price index jointly with the labor-market constraint $(L M C)$ we can compute the equilibrium number of firms under symmetry:

$$
M_{i i}=\frac{\alpha(1+k-\sigma) \psi}{2 \sigma\left[f^{d}(1+k-\sigma)+\gamma(k \phi+\sigma-1)\right]} .
$$

Using the total derivatives of the labor market constraint $(L M C)$ together with the total differential of the trade balance condition $(T B)$ - both evaluated at $\lambda=1 / 2$ - we can compute $\frac{d w_{i}}{d \lambda}$ and $\frac{d M_{i i}}{d \lambda}$. Finally, we need to compute the total derivative of the price index and evaluate it at $\lambda=1 / 2$ as well. Plugging in $\frac{d w_{i}}{d \lambda}, \frac{d M_{i i}}{d \lambda}$, and $d P\left(\frac{d w_{i}}{d \lambda}, \frac{d M_{i i}}{d \lambda}\right)$ into the definition of the break point from (D.2) we get the following condition that describes the critical parameter constellation for the symmetric equilibrium to just become unstable:

$$
\begin{aligned}
& \frac{(\sigma-1)^{2}(\phi-1)}{\alpha \sigma(\phi+1)}\left[\gamma \phi-A\left(c+f^{d}\right)\right]= \\
& \left(c+f^{d}\right)(\sigma-1) A+\gamma \phi(1+2 k-\sigma)-\frac{2 k^{2} \gamma \phi\left[\left(c+f^{d}\right) A+\gamma \phi\right]}{f^{d}(k-\sigma+1)+\gamma(k \phi+\sigma-1)},
\end{aligned}
$$

where $A=\frac{1-\alpha}{1+\alpha}$. This condition yields the break point $\tau_{B}$ and it is plotted for different parameter constellations in Figure 4 


\section{References}

Acemoglu, D. and F. Zilibotti (1997), Was Prometheus Unbound by Chance? Risk, Diversification, and growth, Journal of Political Economy 105, 709-51.

Alfaro, L., A. Chanda, S. Kalemli-Ozcan, and S. Sayek (2004), FDI and economic growth: The role of local financial markets, Journal of International Economics 64, 89-112.

Antràs, P. and R.J. Caballero (2009), Trade and capital flows: A financial frictions perspective, Journal of Political Economy 117, 701-744.

Antràs, P., M.A. Desai and C.F. Foley (2009), Multinational firms, FDI flows, and imperfect capital markets, Quarterly Journal of Economics 124, 1171-1219.

Baldwin, R.E., R. Forslid, P. Martin, G.I.P. Ottaviano, and F. Robert-Nicoud (2003), Economic geography and public policy. Princeton University Press, Princeton, NJ.

Beck, T. (2002), Financial development and international trade. Is there a link?, Journal of International Economics 57, 107-131.

Beck, T. (2003), Financial dependence and international trade, Review of International Economics 11, 296-316.

Beck, T., A. Demirgüç-Kunt, and R. Levine (2000), A new database on the structure and the development of the financial sector, World Bank Economic Review 14, 597-605.

Brülhart, M. and F. Sbergami (2009), Agglomeration and growth: Cross-country evidence, Journal of Urban Economics 65, 48-63.

Brülhart, M. and R. Traeger (2005), An account of geographic concentration patterns in Europe, Regional Science and Urban Economics 35, 597-624.

Carlin, W. and C. Mayer (2003), Finance, investment, and growth, Journal of Financial Economics 69, 191-226.

Chor, D., F. Foley and K. Manova (2008), Host country financial development and MNC activity, Stanford University, mimeo. 
Claessens, S. and L. Laeven (2003), Financial development, property rights, and growth, Journal of Finance 58, 2401-2436.

Combes, P.-P., T. Mayer, and J.-F. Thisse (2008), Economic geography: The integration of regions \& nations. Princeton: Princeton University Press.

Davis, D. and D. Weinstein (2002), Bones, bombs, and break points: the geography of economic activity, American Economic Review 92, 1269-1289.

Davis, D. and D. Weinstein (2003), Market access, economic geography and comparative advantage: an empirical assessment, Journal of International Economics 59, 1-23.

Egger, H. and U. Kreickemeier (2008), Firm heterogeneity and the labor market effects of trade liberalization, International Economic Review 50, 187-216.

Egger, H. and U. Kreickemeier (2012), Fairness, trade, and inequality, Journal of International Economics 86, 87-96.

Egger, P. and C. Keuschnigg (2010a), Innovation, trade and finance, Working Paper.

Egger, P. and C. Keuschnigg (2010b), Corporate finance and comparative advantage, Working Paper.

Ehrlich, M. v. and T. Seidel (2012), More similar firms - more similar regions? On the role of firm heterogeneity for agglomeration, CESifo Working Paper No. 4028.

Ellison, G., E.L. Glaeser, and W.R. Kerr (2010), What causes industry agglomeration? Evidence from coagglomeration patterns, American Economic Review 100, $1195-1213$.

Felbermayr, G., J. Prat and H.-J. Schmerer (2011), Globalization and labor market outcomes: Wage bargaining, search frictions, and firm heterogeneity, Journal of Economic Theory 146, 39-73.

Fujita, M., P. Krugman and A. Venables (1999), The spatial economy: Cities, regions, and international trade. Cambridge: MIT Press.

Gwartney, J., R. Lawson and J. Hall (2012), 2012 Economic freedom dataset, published in: Economic freedom of the world: 2012 annual report. Fraser Institute. 
Hakenes, H. and J. Kranich (2010), Capital market frictions and economic geography, unpublished manuscript, University of Hannover.

Hanson, G.H. and C. Xiang (2004), The home-market effect and bilateral trade patterns, American Economic Review 94, 1108-1129.

Helpman, E. and O. Itskhoki (2010), Labor market rigidities, trade and unemployment, Review of Economic Studies 77, 1100-1137.

Helpman, E., O. Itskhoki, and S. Redding (2010), Inequality and unemployment in a global economy, Econometrica 78, 1239-1283.

Holmstrom, B. and J. Tirole (1997), Financial intermediation, loanable funds, and the real sector, Quarterly Journal of Economics 112, 663-691.

Kletzer, K. and P. Bardhan (1987), Credit markets and patterns of international trade, Journal of Development Economics 27, 57-70.

Krugman, P. (1980), Scale Economies, Product Differentiation, and the Pattern of Trade, American Economic Review 70, 950-959.

Krugman, P. (1981), Trade, accumulation, and uneven development, Journal of Development Economics 8, 149-161.

Krugman, P. (1991), Increasing returns and economic geography, Journal of Political Economy 99, 483-499.

Krugman, P. and A. Venables (1995), Globalization and the inequality of nations, Quarterly Journal of Economics 110, 857-880.

Lewis, W.A. (1977), The evolution of international economic order, Princeton: Princeton University Press.

Manova, K. (2008), Credit constraints, equity market liberalizations and international trade, Journal of International Economics 76, 33-47.

Manova, K. (2012), Credit constraints, heterogeneous firms and international trade, Review of Economic Studies, forthcoming.

Martin, P. and H. Rey (2004), Financial super-markets: Size matters for asset trade, Journal of International Economics 64, 335-361. 
Maskus, K.E., R. Neumann and T. Seidel (2012), How national and international financial development affect industrial R\&D, European Economic Review 56, 72-83.

Melitz, M.J. (2003), The impact of trade on intra-industry reallocations and aggregate industry productivity, Econometrica 71, 1695-1725.

Muûls, M. (2008), Exporters and credit constraints. A firm-level approach, National Bank of Belgium Working Paper No. 139.

Myrdal, G. (1957), Economic theory and underdeveloped regions, London: Duckworth.

Pflüger, M. and J. Südekum (2012), Subsidizing firm entry in open economies, Journal of Public Economics, forthcoming.

Rajan, R.G. and L. Zingales (1998), Financial dependence and growth, American Economic Review 88, 559-586.

Redding, S.J. and D.M. Sturm (2008), The costs of remoteness: Evidence from German division and reunification, American Economic Review 98, 1766-1797.

Tirole, J. (2006), The theory of corporate finance. Princeton: Princeton University Press. 